\title{
Shortwave direct radiative effects of above-cloud aerosols over global oceans derived from 8 years of CALIOP and MODIS observations
}

\author{
Zhibo Zhang ${ }^{1,2}$, Kerry Meyer ${ }^{3,4}$, Hongbin $\mathbf{Y u}^{3,5}$, Steven Platnick ${ }^{3}$, Peter Colarco ${ }^{3}$, Zhaoyan Liu ${ }^{6,7}$, and \\ Lazaros Oreopoulos ${ }^{3}$ \\ ${ }^{1}$ Physics Department, University of Maryland Baltimore County (UMBC), Baltimore, Maryland, USA \\ ${ }^{2}$ Joint Center of Earth System Technology (JCET), UMBC, Baltimore, Maryland, USA \\ ${ }^{3}$ NASA Goddard Space Flight Center, Greenbelt, Maryland, USA \\ ${ }^{4}$ Goddard Earth Science Technology and Research (GESTAR), Universities Space Research Association, Columbia, \\ Maryland, USA \\ ${ }^{5}$ Earth System Science Interdisciplinary Center (ESSIC), University of Maryland, College Park, Maryland, USA \\ ${ }^{6}$ Science Systems and Applications, Inc. (SSAI), Lanham, Maryland, USA \\ ${ }^{7}$ NASA Langley Research Center, Hampton, Virginia, USA
}

Correspondence to: Zhibo Zhang (zhibo.zhang@umbc.edu)

Received: 8 September 2015 - Published in Atmos. Chem. Phys. Discuss.: 29 September 2015

Revised: 11 February 2016 - Accepted: 11 February 2016 - Published: 4 March 2016

\begin{abstract}
In this paper, we studied the frequency of occurrence and shortwave direct radiative effects (DREs) of abovecloud aerosols (ACAs) over global oceans using 8 years (2007-2014) of collocated CALIOP and MODIS observations. Similar to previous work, we found high ACA occurrence in four regions: southeastern (SE) Atlantic region, where ACAs are mostly light-absorbing aerosols, i.e., smoke and polluted dust according to CALIOP classification, originating from biomass burning over the African Savanna; tropical northeastern (TNE) Atlantic and the Arabian Sea, where ACAs are predominantly windblown dust from the Sahara and Arabian deserts, respectively; and the northwestern (NW) Pacific, where ACAs are mostly transported smoke and polluted dusts from Asian. From radiative transfer simulations based on CALIOP-MODIS observations and a set of the preselected aerosol optical models, we found the DREs of ACAs at the top of atmosphere (TOA) to be positive (i.e., warming) in the SE Atlantic and NW Pacific regions, but negative (i.e., cooling) in the TNE Atlantic Ocean and the Arabian Sea. The cancellation of positive and negative regional DREs results in a global ocean annual mean diurnally averaged cloudy-sky DRE of $0.015 \mathrm{~W} \mathrm{~m}^{-2}$ (range of -0.03 to $0.06 \mathrm{~W} \mathrm{~m}^{-2}$ ) at TOA. The DREs at surface and within the atmosphere are $-0.15 \mathrm{~W} \mathrm{~m}^{-2}$ (range of
\end{abstract}

-0.09 to $-0.21 \mathrm{~W} \mathrm{~m}^{-2}$ ), and $0.17 \mathrm{~W} \mathrm{~m}^{-2}$ (range of 0.11 to $0.24 \mathrm{~W} \mathrm{~m}^{-2}$ ), respectively. The regional and seasonal mean DREs are much stronger. For example, in the SE Atlantic region, the JJA (July-August) seasonal mean cloudy-sky DRE is about $0.7 \mathrm{~W} \mathrm{~m}^{-2}$ (range of 0.2 to $1.2 \mathrm{~W} \mathrm{~m}^{-2}$ ) at TOA. All our DRE computations are publicly available ${ }^{1}$. The uncertainty in our DRE computations is mainly caused by the uncertainties in the aerosol optical properties, in particular aerosol absorption, the uncertainties in the CALIOP operational aerosol optical thickness retrieval, and the ignorance of cloud and potential aerosol diurnal cycle. In situ and remotely sensed measurements of ACA from future field campaigns and satellite missions and improved lidar retrieval algorithm, in particular vertical feature masking, would help reduce the uncertainty.

\footnotetext{
${ }^{1} \mathrm{https}: / /$ drive.google.com/folderview?id= 0B6gKx4dgNY0GMVYzcEd0bkZmRmc\&usp=sharing
} 


\section{Introduction}

Although most tropospheric aerosols are emitted into the atmospheric boundary layer, they can be convectively lifted above low-level clouds, or in some cases they are emitted at altitudes higher than the boundary layer and are subsequently transported over low-level cloud decks. In fact, above-cloud aerosols (ACAs) have been observed in several regions of the globe (Devasthale and Thomas, 2011; Winker et al., 2013). $\mathrm{ACA}$ is an important component of the climate system because its interactions (scattering and absorption) with shortwave (SW) solar radiation (so-called direct radiative effect) could differ substantially from that of clear-sky aerosols or below cloud aerosols, particularly for absorbing particles. In this study we focus only on the SW direct radiative effect (DRE), which for the sake of clarity we will refer to as DRE for short. The DRE of aerosols at the top of the atmosphere (TOA) is strongly dependent on the underlying surface. Over dark surfaces, the scattering effect of aerosols is generally dominant, leading to a negative DRE (i.e., cooling) at TOA. In contrast, when aerosols reside above clouds, aerosol absorption of solar radiation can be significantly enhanced by cloud reflection, which can offset or even exceed the scattering effect of the aerosol (depending on the aerosol radiative properties) and can yield a less negative or even positive (i.e., warming) DRE at TOA (Abel et al., 2005; Chand et al., 2009; Keil and Haywood, 2003; Meyer et al., 2013; Zhang et al., 2014). The larger the cloud reflection, the more likely the positive DRE will occur. Thus, an accurate quantification of ACA DRE is needed to improve the understanding of aerosol effects on the radiative energy balance and climate. In the past decade, the DRE of aerosols in clear-sky conditions has been thoroughly studied and relatively well constrained by satellite and in situ data (Yu et al., 2006). However, due to traditional aerosol remote sensing techniques, in particular those using passive sensors, are limited only to clear-sky conditions, the DRE of ACA had been largely unexplored until recently. Moreover, model simulations of ACA DRE show extremely large disparities (Schulz et al., 2006).

Recent advances in active and passive remote sensing techniques have filled this data gap and have provided an excellent opportunity for studying the DRE of ACA (Yu and Zhang, 2013). The Cloud-Aerosol Lidar with Orthogonal Polarization (CALIOP) onboard NASA's Cloud-Aerosol Lidar and Infrared Pathfinder Satellite Observations (CALIPSO) satellite was launched in 2006 as part of NASA's A-Train satellite constellation (Stephens et al., 2002; Winker et al., 2007). As an active lidar with depolarization and two wavelengths, CALIOP is able to measure the vertical distribution of aerosol backscatter, extinction, particle depolarization ratio, and color ratio for clear-sky aerosols, ACA, and aerosol below thin high-level clouds. These measurements, combined with cloud observations from CALIOP itself and other A-train instruments have provided a revolutionary global view of the vertical distribution of aerosols and clouds (e.g.,
Winker et al., 2013). In addition to vertical feature masking, CALIOP also provides operational retrievals of a variety of aerosol properties, such as aerosol type classification, aerosol layer height, aerosol optical thickness (AOT), and aerosol extinction profile, for both clear-sky aerosols and ACA.

Although CALIOP is the first to provide quantitative measurements of ACA on an operational basis, its narrow alongtrack sampling leaves large spatial gaps in the observations. In recent years, several attempts have been made to detect ACAs and retrieve their properties from passive imagers with much better spatial sampling than CALIOP. Waquet et al. (2009) developed a method based on multi-angular polarization measurements from the Polarization and Directionality of the Earth Reflectances (POLDER) to retrieve abovecloud aerosol optical thickness (AOT) (Waquet et al., 2013a). Torres et al. (2011) developed an algorithm of simultaneously retrieving ACA properties for smoke and cloud optical thickness (COT) from ultraviolet (UV) aerosol index (AI) derived from the Ozone Monitoring Instrument (OMI). Jethva et al. (2013) retrieved simultaneously the above-cloud AOT and COT from the spectral dependence of visible and near-infrared cloud reflectance as observed by the Moderate Resolution Imaging Spectroradiometer (MODIS). Similarly, Meyer et al. (2015) developed a multispectral optimal inversion technique to retrieve ACA AOT, COT, and cloud effective particle radius (CER) from MODIS. A review of the emerging satellite-based ACA observations can be found in Yu and Zhang (2013). These emerging techniques based on passive sensors will provide insights into ACA and their radiative effects over much broader regions in the future. At present, however, they are primarily at the research level and no operational data are yet available.

The ACA DRE can be calculated with radiative transfer models using the retrieved ACA AOT, COT and preselected aerosol optical properties. This approach is referred to as the forward calculation method. Chand et al. (2009) aggregated CALIOP above-cloud AOT retrievals (Chand et al., 2008) and Terra MODIS cloud products to monthly means at $5^{\circ} \times 5^{\circ}$ grids and calculated the radiative effects of transported smoke above the low-level stratocumulus deck in the SE Atlantic. This spatial-temporal aggregation of the satellite data obscures the potential influence of cloud and aerosol sub-grid variability on the DRE, which could lead to significant uncertainty (Min and Zhang, 2014). The use of operational MODIS COT could also bias the DRE low (less positive or more negative) because of the low bias of MODIS COT induced by overlying light-absorbing aerosols (Coddington et al., 2010; Haywood et al., 2004). In Meyer et al. (2013), the MODIS COT bias due to ACA contamination was corrected using collocated CALIOP above-cloud AOT observations, and the unbiased MODIS cloud properties and CALIOP above-cloud AOT were used to calculate pixel-level cloudy sky ACA DRE. Such rigorous collocation has an obvious advantage as it takes into account the spatial-temporal variability of clouds and aerosols. However, it is computa- 
tionally expensive and requires large amounts of pixel-level data. Recently, Zhang et al. (2014) developed a novel statistical method of computing ACA DRE based on the fact that ACA AOT and COT are generally randomly overlapped. This method greatly improves the ACA DRE computation efficiency while maintaining the same level of accuracy as the pixel-level computations. The high efficiency of this method enables us to compute 8 years of ACA DRE over global oceans in this study.

In the forward calculation approach discussed above, the DRE depends on the selection of aerosol optical properties, in particular the single scattering albedo. Alternatively, other approaches allow for bypassing the aerosol optical property assumption. For example, Peters et al. (2011), Wilcox (2012), and more recently (Feng and Christopher, 2015) estimated the DRE of ACA through regression of multiple satellite data sets from the A-Train, including OMI UV AI, CERES (Clouds and the Earth's Radiant Energy System), and AMSER-E (Advanced Microwave Scanning Radiometer for EOS). de Graaf et al. (2012) developed a method that takes advantage of the wide spectral coverage of the space-borne Scanning Imaging Absorption Spectrometer for Atmospheric Chartography (SCIAMACHY). They first inferred cloud parameters (e.g., COT and CER) from the SCIAMACHY observations in the short-wave infrared region (i.e., 1.2 and $1.6 \mu \mathrm{m}$ ), where the impact of ACA on cloud reflectance is generally minimal. Then, they estimate the DRE from the difference between the SCIAMACHY observed cloud reflectance spectrum (i.e., polluted) and that of a computed (i.e., clean) spectrum derived from the inferred cloud parameters. These studies thus minimized the impact of aerosol retrieval uncertainty in the DRE estimate. On the other hand, these studies only provided estimates of the instantaneous DRE of ACA at the satellite crossing time and only at TOA, which is often not adequate for climate studies and model evaluations. DRE at surface and within the atmosphere are required to assess the full impact of aerosols on climate, and models often report diurnally averaged DRE.

Although the abovementioned studies have shed important light on the radiative effects of ACA on the climate system, several aspects of ACA remain unexplored. First, there is a lack of a global and multiyear perspective since almost all previous studies have focused on the SE Atlantic Ocean and have taken place over a limited time period. Second, most studies have only reported instantaneous DRE at TOA, which is not adequate for climate studies and model evaluations. In addition, the impact of retrieval uncertainties in satellite products (e.g., CALIOP aerosol and MODIS cloud products) on computed DRE has not been sufficiently assessed.

The objective of this study is to derive estimates of the diurnally averaged DRE of ACA over global oceans from collocated CALIOP and MODIS observations over 8 years (2007-2014). This is the first observation-based study (as far as we are aware) that provides a global and multiyear perspective of the DRE of ACA. In addition to the DRE at
TOA, we also calculate the DRE of ACA at the surface and within the atmosphere. The diurnal variation of solar radiation is fully accounted for in this study, making our results more directly comparable to the model reports of the diurnally averaged DRE, though it is important to note that the diurnal variation of the underlying cloud properties are not considered. Moreover, we carried out a series of sensitivity tests to estimate the impact of the uncertainties associated with aerosol scattering properties and satellite retrieval bias on the DRE results. The rest of this paper is organized as follows: Sect. 2 describes the satellite products used to derived the global distribution of ACA; Sect. 3 discusses the global distribution and seasonal variability of ACA; Sect. 4 briefly overviews the method used to derive the DRE of ACA; and Sect. 5 details the results. The major uncertainties in DRE computation are assessed in Sect. 6. The main findings and conclusions are summarized in Sect. 7.

\section{Satellite data}

In this study, we use the CALIOP Version 3 level-2 aerosol and cloud layer products to derive the statistics of ACA properties and the MODIS Collection 6 (C6) level-3 daily gridded cloud product for cloud property statistics. This section provides a brief overview of these products, including the potential biases and uncertainties.

\subsection{CALIOP}

The CALIOP Version 3 level-2 aerosol and cloud layer products (Winker et al., 2009), at a nominal $5 \mathrm{~km}$ horizontal resolution (product names "CAL_LID_L2_05kmALay" and "CAL_LID_L2_05kmCLay"), are used to first identify ACA pixels, and then to derive aerosol layer properties, including aerosol type, AOT and layer top and bottom height. The CALIOP level-2 retrieval algorithm detects aerosol and cloud layers, and records their top and bottom heights and layer integrated properties using a "feature finder" algorithm and cloud-aerosol discrimination (CAD) algorithm (Liu et al., 2009). The detected aerosol layers are further classified into six sub-types (polluted continental, biomass burning, desert dust, polluted dust, clean continental and marine) (Omar et al., 2009), and the detected cloud layers are assigned different thermodynamic phases (Hu et al., 2007) based on the observed backscatter, color ratio and depolarization ratio. The extinction of an aerosol or cloud layer is derived from the attenuated backscatter profile using a priori lidar ratios, preselected based on aerosol sub-type and cloud phase (Young and Vaughan, 2008). In the case where clear air is available both above and below a layer, a constrained retrieval is performed to derive the lidar ratio as well as the extinction and backscatter coefficient for the layer.

The CALIOP lidar is known to have several inherent limitations. First, it has very limited spatial sampling, provid- 
ing observations only along its ground track. Thus computing the DRE of ACA over a given latitude-longitude grid box necessarily requires assuming that the aerosol property statistics retrieved by CALIOP along its track represent the statistics over the whole grid box. Moreover, the limited spatial sampling also inhibits the use of CALIOP to study the variations of ACA and its DRE at small temporal (e.g., interannual variability) or spatial scales (e.g., smoke or dust outbreak event). Another limitation of CALIOP is that its daytime aerosol retrievals generally have larger uncertainty in comparison with nighttime retrievals caused by strong background solar noise (Hunt et al., 2009). Some recent studies have noted significant differences between daytime and nighttime CALIOP aerosol property retrievals, in particular the AOT retrievals, which is partly caused by the solar background noise issue (Meyer et al., 2013; Winker et al., 2013). The impact of daytime vs. nighttime CALIOP aerosol retrieval differences on the DRE of ACA is investigated in the uncertainty analysis detailed in Sect. 6 .

In addition to the sampling limitations, several recent studies have found that CALIOP daytime AOT retrievals for ACA, in particular above-cloud smoke, are significantly smaller compared to collocated results from other techniques (Jethva et al., 2014; Torres et al., 2013; Waquet et al., 2013b) and results retrieved from the CALIOP level 1 data using an opaque water cloud (OWC) constrained technique (Liu et al., 2015). The cause for the bias is complex, and multiple sources can contribute to the AOT retrieval uncertainties (Liu et al., 2015), but the main issue is the failure of the current CALIOP retrieval algorithm to detect the full physical thickness of dense smoke layers. Smoke aerosol generally has a large attenuation at $532 \mathrm{~nm}$ that is $2-3$ times larger than that at $1064 \mathrm{~nm}$. The current CALIOP algorithms detect features based solely on the $532 \mathrm{~nm}$ data. Strong attenuation in dense smoke layers can make the detection of the true base of dense smoke layers very difficult. (This may be improved largely if the feature detection is performed at both 532 and $1064 \mathrm{~nm}$.) As a result, the current CALIOP feature detection algorithm often fails to detect the full extent of dense aerosol layers, leading to low biases in retrieved AOT (Jethva et al., 2014; Liu et al., 2015; Torres et al., 2013). This underestimation of AOT apparently can have significant impact on the DRE computation. We have developed a simple method to estimate the upper limit of this impact, which is detailed in Sect. 6.

\subsection{MODIS}

In this study, we use the Collection 6 (C6) level-3 gridded daily Atmosphere product from Aqua-MODIS (product name MYD08_D3) for the statistics of cloud properties and other parameters, such as solar zenith angle, needed for ACA DRE computations. The MYD08_D3 product contains gridded scalar statistics and histograms computed from the level-2 (i.e., pixel-level) MODIS products. As summarized in
Platnick et al. (2003), the operational level-2 MODIS cloud product provides cloud masking (Ackerman et al., 1998), cloud top height retrieval based on $\mathrm{CO}_{2}$ slicing or the infrared window method (Menzel et al., 1983), cloud top thermodynamic phase determination (Baum et al., 2012; Marchant et al., 2015; Menzel et al., 2006), and cloud optical and microphysical property retrieval based on the bi-spectral solar reflectance method (Nakajima and King, 1990). Level-3 aggregations include a variety of scalar statistical information (mean, standard deviation, $\max / \mathrm{min}$ occurrences) and histograms (marginal and joint) (Hubanks et al., 2008). A particularly useful level-3 cloud product for this study is the daily joint histogram of COT vs. cloud top pressure (CTP), derived using daily counts of successful daytime level-2 pixel retrievals that fall into each joint COT-CTP bin. Eleven COT bins, ranging from 0 to 100 , and $13 \mathrm{CTP}$ bins, ranging from 200 to $1000 \mathrm{mb}$, comprise the histogram. As discussed below, the COT-CTP joint histogram allows for identification of the portion of the cloud population that lays beneath the aerosol layer found by CALIOP, as well as the corresponding COT probability distribution needed for DRE estimation. In addition to the COT-CTP joint histogram, we also use the gridded mean solar and sensor zenith angles for calculating instantaneous DRE and correcting the COT bias due to the presence of ACA.

A major issue with MODIS data for ACA DRE computation is the potential COT retrieval bias in the presence of significant overlying ACA. As noted in several previous studies, an overlying layer of light-absorbing aerosol, e.g., smoke, makes the scene appear darker than the otherwise clean cloud. This cloud-darkening effect often leads to a significant underestimate of MODIS COT for scenes with smoke overlying clouds (e.g., Coddington et al., 2010; Haywood et al., 2004; Meyer et al., 2013). A fast COT correction scheme has previously been developed (Zhang et al., 2014) to account for the COT retrieval bias due to ACA, which is briefly overviewed in Sect. 4.3.

\section{Global distribution of ACA}

The present study is limited to ocean scenes only. This decision was made for a number of reasons. First, ACA occurs much more frequently over ocean than over land (see Fig. 3 of Devasthale and Thomas, 2011). Second, the contrast between ACA DRE and clear-sky aerosol DRE is generally larger over ocean than over land because the contrast between the ocean surface and cloud is larger than the contrast between the land surface and cloud. Finally, the large spatial and spectral variability of land surface reflectance makes the radiative transfer computation much more complicated than that over the ocean. For these reasons, we limit our analysis only to global oceans and leave the DRE of ACA over land for future study. 


\subsection{ACA identification and classification}

The following criteria are used to identify ACA columns within the CALIOP $5 \mathrm{~km}$ layer products: (1) the CALIOP $5 \mathrm{~km}$ cloud layer product identifies at least one layer of liquid phase cloud in the profile; (2) the CALIOP $5 \mathrm{~km}$ aerosol layer product identifies at least one layer of aerosol in the profile; (3) the "Layer_Base_Altitude" of the lowest aerosol layer is higher than the "Layer_Top_Altitude" of the highest cloud layer. The last criterion excludes some complicated scenarios, such as aerosol layers in between low and high level clouds, while retaining the majority of ACA cases. Following the best practice advice of the CALIOP science team (Winker et al., 2013), we used various data quality assurance metrics and flags to screen out low-confidence aerosol layers. Specifically, we only accept ACA layers with the following properties: (i) cloud aerosol discrimination score values for the identified aerosol layer between -20 to -100 ; (ii) extinction QC values of 0 or 1; and (iii) feature optical depth uncertainty smaller than 99.9. Any columns that do not satisfy the above criteria were classified as either clear sky if no cloud is found in the column or "clean" cloud if one or more cloud layers are present.

After ACA identification, we further classify the ACA layer into the six aerosol sub-types (clean marine, dust, polluted continental, clean continental, polluted dust and smoke) provided by the CALIOP product (Omar et al., 2009). The classification is needed later to select the aerosol optical properties to be used in the DRE computation. It should be noted that the CALIOP operational algorithm often identifies different sub-types for vertically adjacent aerosol layers (Meyer et al., 2013). Recent studies indicate that this is a misclassification issue in the current CALIOP operational algorithm (Liu et al., 2015; Meyer et al., 2013). Uncertainty in aerosol classification by CALIOP operational algorithms is also highlighted in comparisons to airborne High Spectral Resolution Lidar (HSRL) observations, which retrieve directly the aerosol lidar ratio (Burton et al., 2013). These observations suggest highest uncertainty in aerosol typing for smoke and polluted dust cases. Aerosol type misclassification where CALIOP operational algorithms identify polluted dust is also highlighted in a recent study in which aerosol transport model fields are used to directly simulate the CALIOP aerosol typing and compared to native aerosol fields within the model (Nowottnick et al., 2015). In this study, we associate all ACA layers in a single profile with only one sub-type, namely the sub-type of the layer with the largest AOT. This classification scheme reduces the complication caused by aerosol misclassification in radiative transfer simulations.

\subsection{Occurrence frequency of ACA}

After the identification of ACA cases in CALIOP data, we first investigate the geographical and seasonal variations of the occurrence frequency of ACA over global oceans. It should be noted that clouds can have a strong diurnal cycle; thus the occurrence frequency of ACA might also have a significant diurnal cycle. Unfortunately, because CALIOP is in a sun-synchronous polar orbit, it can provide only two snapshots of this diurnal cycle over most of the globe (except for polar regions), one during daytime (i.e., ascending local equatorial crossing time $1.30 \mathrm{p} . \mathrm{m}$ ) and the other during nighttime (i.e., descending local equatorial crossing time 1.30 a.m.). Here we define the ACA occurrence frequency $\left(f_{\mathrm{ACA}}\right)$ in a latitude-longitude box as the ratio of ACA columns to total cloudy columns sampled by CALIOP:

$$
f_{\mathrm{ACA}}\left(t^{*}\right)=\sum_{i=1}^{6} f_{\mathrm{ACA}, i}\left(t^{*}\right)=\sum_{i=1}^{6} \frac{N_{\mathrm{ACA}, i}}{N_{\mathrm{cloudy}}},
$$

where $t^{*}$ signifies that the $f_{\mathrm{ACA}}$ is observed at the CALIOP crossing time; $f_{\mathrm{ACA}}$ is the fraction of cloudy columns covered by the $i$ th type of aerosol, $N_{\text {cloudy }}$ is the total number of cloudy columns sampled by CALIOP within the grid, and $N_{\mathrm{ACA}, i}$ is the number of ACA columns that have been identified as the $i$ th type of aerosol by CALIOP. This is different from the definition in Devasthale and Thomas (2011), in which the occurrence frequency is defined as the ratio of ACA columns to the total number of CALIOP observations. As such, the two definitions differ by a factor of $f_{\mathrm{c}}$, the total cloud fraction. We define the occurrence frequency in this way because the $f_{\mathrm{ACA}}$ provides information additional to and independent of the total cloud fraction $f_{\mathrm{c}}$ that can help, for example, modelers understand whether an inadequate simulation of ACA is due to cloud and/or aerosol simulation. On the other hand, one has to couple our $f_{\mathrm{ACA}}$ together with $f_{\mathrm{c}}$ to depict a complete picture.

Figures 1 and 2 show the seasonal variation of total cloud fraction $f_{\mathrm{c}}$ and $f_{\mathrm{ACA}}$, respectively, over global ocean derived from daytime CALIOP observations. There are several ACA frequency "hotspots" that can be clearly seen in Fig. 2, from which four primary ACA regions can be defined (see Table 1). The types of ACA in each region according to the CALIOP aerosol classification product are shown in Fig. 3.

1. SE Atlantic Ocean - This region is perhaps the most prominent ACA region during the boreal summer (JJA) and fall (SON) seasons (Fig. $2 \mathrm{c}$ and d). The ACA over the SE Atlantic primarily originates from the seasonal burning activities throughout the African Savanna (Eck et al., 2013; Ichoku et al., 2003; Myhre et al., 2003). Prevailing easterly winds in the free troposphere during this season often transport the biomass burning aerosols to the west, off the continent and over the ocean (Matichuk et al., 2007; Swap et al., 1996), where extensive marine boundary layer clouds persist for most of the year leading to a near-persistent seasonal smoke layer above the stratocumulus deck. As shown in Fig. 3a, the ACAs in this region are primarily a mix of smoke and polluted dust. 

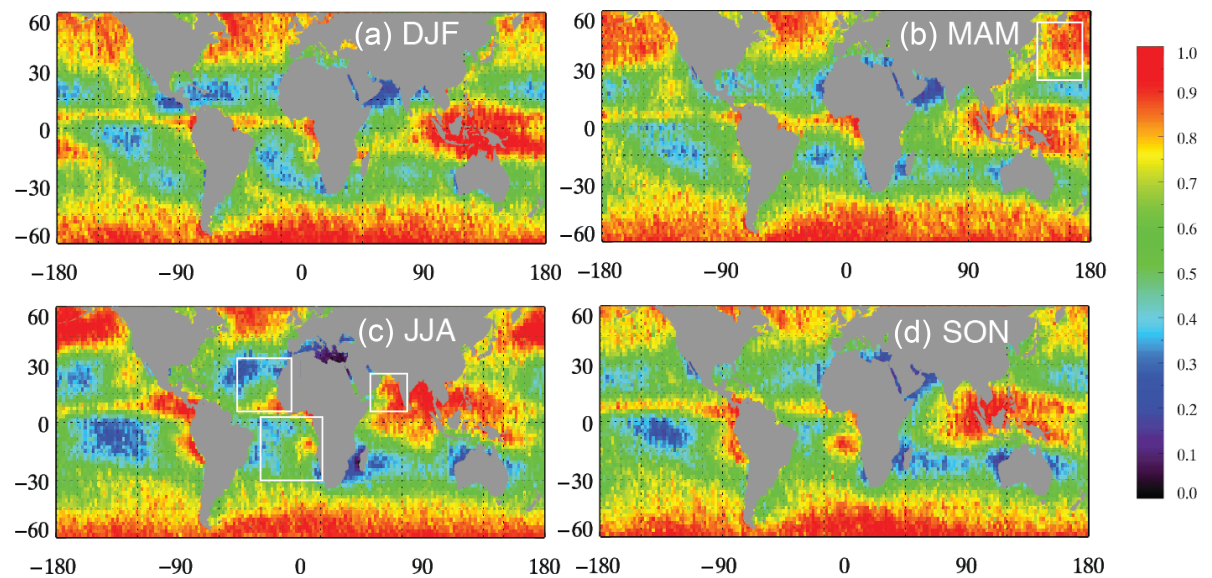

Figure 1. Multiyear seasonal mean total cloud fraction in (a) DJF, (b) MAM, (c) JJA and (d) SON derived from 8 years of daytime CALIOP observations.
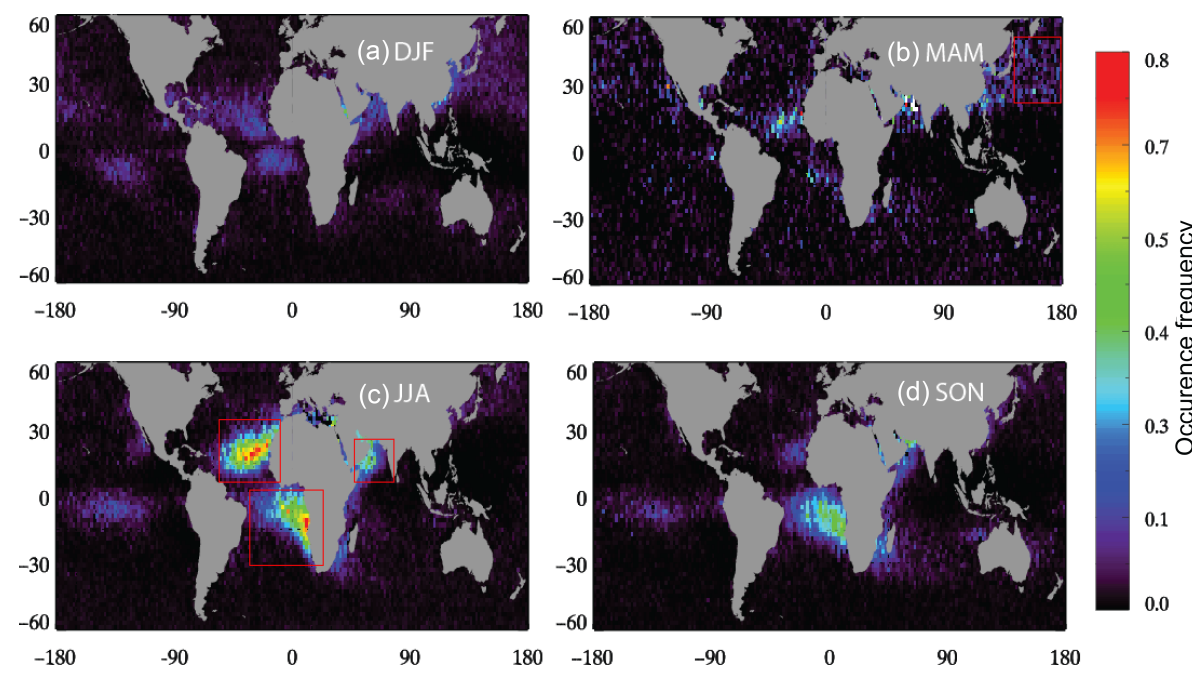

Figure 2. Multiyear seasonal mean occurrence frequency of ACA $\left(f_{\mathrm{ACA}}\right)$ in (a) DJF, (b) MAM, (c) JJA and (d) SON derived from 8 years of daytime CALIOP observations. The red boxes indicate the four regions with high ACA occurrence frequency. See also Table 1 for the exact geolocation.

2. Tropical northeastern (TNE) Atlantic - During boreal spring (MAM) and summer (JJA) (Fig. 2b and c), the dry and dust-laden Saharan Air Layer overlies the cooler, more-humid and cloudy tropical Atlantic Ocean. Not surprisingly, dust is the dominant type of ACA in this region as shown in Fig. 3b.

3. Arabian Sea - During the Asian monsoon season (JJA), the cloud fraction increases to more than $90 \%$, setting the stage for ACA from the transported dust aerosols from the surrounding deserts.

4. Northwestern (NW) Pacific Ocean - During the springtime, the industrial pollution and dust aerosols from Asia carried by the jet stream can travel thousands of miles to the NW Pacific Ocean where cloud fraction is high throughout the year. ACA in this region is a mixture of smoke, dust and polluted dust.

\section{Methodology for computing ACA DRE}

After the identification of ACAs, we use the method described in Zhang et al. (2014) to calculate shortwave ACA DRE by using MODIS observations of clouds. This section provides a brief review the key features of this method. 

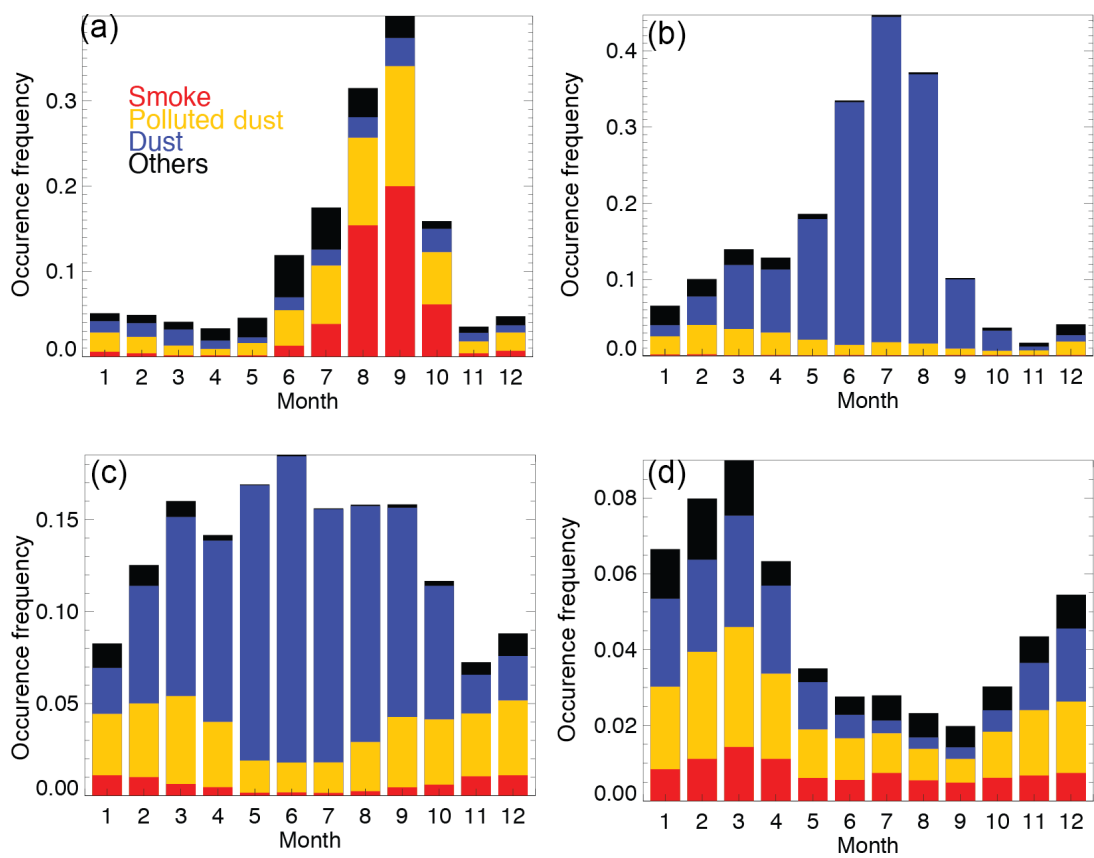

Figure 3. 8-year averaged monthly mean daytime occurrence frequency of aerosol types observed by CALIOP for the (a) southeast Atlantic region, (b) northern tropical Atlantic region, (c) Arabian Sea, and (d) northwestern Pacific.

Table 1. Geo-locations of four active ACA regions.

\begin{tabular}{ll}
\hline Region & Latitude and longitude region \\
\hline $\begin{array}{l}\text { Southeastern } \\
\text { Atlantic }\end{array}$ & $30^{\circ} \mathrm{S}-10^{\circ} \mathrm{N} ; 20^{\circ} \mathrm{W}-20^{\circ} \mathrm{E}$ \\
\hline $\begin{array}{l}\text { Tropical North- } \\
\text { eastern Atlantic }\end{array}$ & $10-30^{\circ} \mathrm{N} ; 45-18^{\circ} \mathrm{W}$ \\
\hline Arabian Sea & $0-30^{\circ} \mathrm{N} ; 40-80^{\circ} \mathrm{E}$ \\
\hline $\begin{array}{l}\text { Northwestern } \\
\text { Pacific }\end{array}$ & $40-55^{\circ} \mathrm{N} ; 145-180^{\circ} \mathrm{E}$ \\
\end{tabular}

\subsection{Definitions of DRE}

For a given latitude-longitude grid box, the grid-mean diurnally averaged shortwave all-sky aerosol radiative effect $\overline{\left\langle\text { DRE }_{\text {all-sky }}\right\rangle}$ is given by

$$
\begin{aligned}
& \overline{\left\langle\mathrm{DRE}_{\text {all-sky }}\right\rangle} \\
& =\frac{1}{24} \int_{t_{\text {surrise }}}^{t_{\text {sunset }}}\left[1-f_{\mathrm{c}}(t)\right]\left\langle\operatorname{DRE}_{\text {clear-sky }}\left[\tau_{\mathrm{a}}(t), \theta_{0}(t)\right]\right\rangle \mathrm{d} t \\
& +\frac{1}{24} \int_{t_{\text {sunrise }}}^{t_{\text {sunset }}} f_{\mathrm{c}}(t)\left\langle\operatorname{DRE}_{\text {cloudy-sky }}\left[\tau_{\mathrm{c}}(t), \tau_{\mathrm{a}}(t), \theta_{0}(t)\right]\right\rangle \mathrm{d} t,
\end{aligned}
$$

where the upper bar ".” indicates the diurnal average and the angle bracket " \langle\rangle " indicates spatial average over the grid box; $f_{\mathrm{c}}(t)$ is the instantaneous cloud fraction, and $\left\langle\operatorname{DRE}_{\text {clear-sky }}(t)\right\rangle$ and $\left\langle\mathrm{DRE}_{\text {cloudy-sky }}(t)\right\rangle$ are the hourly instantaneous DRE averaged over the clear-sky and cloudy-sky region of the grid, respectively. Note that in this study we compute the instantaneous DREs every hour during daytime to capture the diurnally variation of solar radiation. This is why the normalization factor is $1 / 24$ in Eq. (2) and why it needs to be changed accordingly if the instantaneous DREs are computed at a different frequency. For shortwave DRE, the integration range is from local sunrise hour $t_{\text {sunrise }}$ to local sunset hour $t_{\text {sunset }}$ because the DRE during nighttime is zero. Note that the instantaneous $\left\langle\mathrm{DRE}_{\text {clear-sky }}(t)\right\rangle$ is mainly dependent on AOT $\tau_{\mathrm{a}}(t)$ and solar zenith angle $\theta_{0}(t)$. In addition to $\tau_{\mathrm{a}}(t)$ and $\theta_{0}(t),\left\langle\mathrm{DRE}_{\text {cloudy-sky }}(t)\right\rangle$ is also dependent on the COT $\tau_{\mathrm{c}}(t)$. As pointed out in Min and Zhang (2014), in addition to $\theta_{0}(t), f_{\mathrm{c}}(t), \tau_{\mathrm{a}}(t)$, and $\tau_{\mathrm{c}}(t)$ can also have a significant diurnal cycle that influences the diurnal average. However, the orbit of CALIOP only allows it to provide a single snapshot of the diurnal cycle during daytime (another during night time). Because of this limitation, we omit the diurnal variation of $f_{\mathrm{c}}(t), \tau_{\mathrm{a}}(t)$ and $\tau_{\mathrm{c}}(t)$, and only use the value at the daytime CALIOP crossing time $t^{*}$. Nevertheless, we still consider the diurnal variation of solar flux associated by the change of $\theta_{0}(t)$. In such an approximation, we can rewrite the $\overline{\left\langle\mathrm{DRE}_{\text {all-sky }}\right\rangle}$ as follows: 


$$
\begin{aligned}
& \overline{\left\langle\mathrm{DRE}_{\text {all-sky }}\right\rangle} \approx\left[1-f_{\mathrm{c}}\left(t^{*}\right)\right] \overline{\left\langle\mathrm{DRE}_{\text {clear-sky }}^{*}\right\rangle} \\
& +f_{\mathrm{c}}\left(t^{*}\right) \overline{\left\langle\mathrm{DRE}_{\text {cloudy-sky }}^{*}\right\rangle},
\end{aligned}
$$

where the $t^{*}$ corresponds to the daytime CALIOP crossing time (usually 1.30 p.m. local time), $\overline{\left\langle\mathrm{DRE}_{\text {clear-sky }}^{*}\right\rangle}$ and $\overline{\left\langle\mathrm{DRE}_{\text {cloudy-sky }}^{*}\right\rangle}$ are approximate clear-sky and cloudy-sky aerosol DRE. In particular, $\overline{\left\langle\mathrm{DRE}_{\text {cloudy-sky }}^{*}\right\rangle}$ can be integrated from the hourly instantaneous DRE as follows:

$$
\begin{aligned}
& \overline{\left\langle\mathrm{DRE}_{\text {cloudy-sky }}^{*}\right\rangle} \\
& =\frac{1}{24} \int_{t_{\text {sunrise }}}^{t_{\text {sunset }}}\left\langle\operatorname{DRE}_{\text {cloudy-sky }}\left[\tau_{\mathrm{c}}\left(t^{*}\right), \tau_{\mathrm{a}}\left(t^{*}\right), \theta_{0}(t)\right]\right\rangle \mathrm{d} t,
\end{aligned}
$$

where the normalization factor $1 / 24$ is to obtain diurnal mean from hourly computations. Theoretically, cloudy-sky aerosol DRE should include the contributions from aerosols in all conditions, e.g., above, below or in-between clouds. However, it is difficult to measure aerosol properties below clouds from space-borne instruments. Here we simply assume cloudy-sky aerosol DRE is mainly attributed to ACAs. This is a reasonable assumption for TOA DRE, but might introduce large uncertainties to surface and atmospheric DRE. The uncertainty caused by this assumption will be left for future study. Based on this assumption, we can rewrite Eq. (4) as

$$
\begin{aligned}
& \overline{\left\langle\mathrm{DRE}_{\text {cloudy-sky }}^{*}\right\rangle}=f_{\mathrm{ACA}}\left(t^{*} \overline{\left\langle\overline{\left.\mathrm{DRE}_{\mathrm{ACA}}^{*}\right\rangle}\right.}\right. \\
& =f_{\mathrm{ACA}}\left(t^{*}\right) \frac{1}{24} \int_{t_{\text {sunrise }}}^{t_{\text {sunset }}}\left\langle\operatorname{DRE}_{\mathrm{ACA}}\left[\tau_{\mathrm{c}}\left(t^{*}\right), \tau_{\mathrm{a}}\left(t^{*}\right), \theta_{0}(t)\right]\right\rangle \mathrm{d} t,
\end{aligned}
$$

where $f_{\mathrm{ACA}}\left(t^{*}\right)$ is the occurrence frequency of ACA observed at the CALIOP crossing time defined in Eq. (1). An important implicit assumption in Eq. (5) is that when CALIOP cannot detect an aerosol layer, the DRE is essentially zero. Using Eq. (5) we can derive the DRE at TOA $\overline{\left\langle D_{\text {cloudy-sky }}^{*}\right\rangle}$ and at the surface $\overline{\left\langle\operatorname{DRE}_{\text {cloudy-sky }}^{*}\right\rangle_{\text {surface }}}$. The DRE within the atmosphere $\overline{\left\langle D E_{\text {cloudy-sky }}^{*}\right\rangle_{\text {atm }}}$ is calculated as follows:

$$
\begin{gathered}
\overline{\left\langle\mathrm{DRE}_{\text {cloudy-sky }}^{*}\right\rangle_{\mathrm{atm}}}=\overline{\left\langle\mathrm{DRE}_{\text {cloudy-sky }}^{*}\right\rangle_{\mathrm{TOA}}} \\
-\overline{\left\langle\mathrm{DRE}_{\text {cloudy-sky }}^{*}\right\rangle_{\text {surface }} .}
\end{gathered}
$$

Here, it is necessary to point out that what is often reported in previous studies is the instantaneous DRE observed at the CALIOP (or other satellite such as SCIAMACHY) crossing time and averaged over only ACA pixels, namely, $\left\langle\operatorname{DRE}_{\mathrm{ACA}}\left[\tau_{\mathrm{c}}\left(t^{*}\right), \tau_{\mathrm{a}}\left(t^{*}\right), \theta_{0}(t)\right]\right\rangle$. This quantity has obvious limitations (e.g., diurnal variation is ignored) and can be misleading if not accompanied by $f_{\mathrm{ACA}}$ because different instruments or algorithms might have different sensitivities or even definitions of ACA (e.g., OMI AI index vs. CALIOP backscatter). In our view, the diurnally averaged, grid-mean, cloudy-sky DRE, $\overline{\left\langle D^{2} E_{\text {cloudy-sky }}^{*}\right\rangle}$, is more suitable for intercomparison, and also more relevant for climate study and modeling evaluation, on which we shall focus in this study.

\subsection{Computation of instantaneous DRE}

It is clear from Eq. (5), once the instantaneous $\left\langle\operatorname{DRE}_{\mathrm{ACA}}\left[\tau_{\mathrm{c}}\left(t^{*}\right), \tau_{\mathrm{a}}\left(t^{*}\right), \theta_{0}(t)\right]\right\rangle$ is known one can easily derive $\overline{\left\langle D_{\text {DRE }}^{*} \text { cloudy-sky }\right.}$ from the integral. In this section, we explain how the instantaneous DRE is computed from the CALIOP and MODIS products. Hereafter we drop the time dependence for simplicity. As mentioned in Sect. 2.1, the CALIOP operational algorithm classifies aerosol layers into 6 sub-types. Therefore, we can rewrite $\left\langle\mathrm{DRE}_{\text {cloudy-sky }}\right\rangle$ as follows:

$\left\langle\mathrm{DRE}_{\text {cloudy-sky }}\right\rangle=\sum_{i=1}^{6} f_{i}\left\langle\mathrm{DRE}_{\mathrm{ACA}}\right\rangle_{i}$,

where $\left\langle\mathrm{DRE}_{\mathrm{ACA}}\right\rangle_{i}$ is the DRE of the $i$ th type of CALIOP aerosol (e.g., dust, smoke, etc., see Fig. 3), and $f_{i}$ is the frequency of detection of the $i$ th type of aerosol. To compute the $\left\langle\mathrm{DRE}_{\mathrm{ACA}}\right\rangle_{i}$, one could collocate the level-2 CALIOP and MODIS data and compute the DRE pixel-by-pixel as follows:

$\left\langle\operatorname{DRE}_{\mathrm{ACA}}\right\rangle_{i}=\frac{1}{N_{i}} \sum_{j=1}^{N_{i}} \operatorname{DRE}_{\mathrm{ACA}}\left(\tau_{\mathrm{a}, j}, \tau_{\mathrm{c}, j}\right)$,

where $\tau_{\mathrm{a}, j}$ and $\tau_{\mathrm{c}, j}$ are the ACA and cloud optical thicknesses of the $j$ th pixel, respectively. Mathematically, Eq. (8) is equivalent to the following double integral:

$\left\langle\operatorname{DRE}_{\mathrm{ACA}}\right\rangle_{i}=\int_{0}^{\infty}\left[\int_{0}^{\infty} \operatorname{DRE}_{\mathrm{ACA}}\left(\tau_{\mathrm{a}}, \tau_{\mathrm{c}}\right) P_{i}\left(\tau_{\mathrm{a}}, \tau_{\mathrm{c}}\right) \mathrm{d} \tau_{\mathrm{a}}\right] \mathrm{d} \tau_{\mathrm{c}}$,

where $P_{i}\left(\tau_{\mathrm{a}}, \tau_{\mathrm{c}}\right)$ is the joint probability density function (PDF) of the above-cloud AOT of the $i$ th CALIOP aerosol type and below-aerosol COT. Deriving DRE from Eq. (9) or (8) requires large amounts of level-2 CALIOP and MODIS data and pixel-by-pixel collocation and radiative transfer simulations. It is thus too computationally expensive and cumbersome for multiyear global studies.

As shown in Zhang et al. (2014), because the AOT of ACA is generally uncorrelated with the COT below, Eq. (9) can be 
simplified by assuming $P_{i}\left(\tau_{\mathrm{a}}, \tau_{\mathrm{c}}\right)=P_{i}\left(\tau_{\mathrm{a}}\right) P\left(\tau_{\mathrm{c}}\right)$ as follows:

$$
\begin{aligned}
& \left\langle\operatorname{DRE}_{\mathrm{ACA}}\right\rangle_{i} \\
& \quad=\int_{0}^{\infty}\left[\int_{0}^{\infty} \operatorname{DRE}{ }_{\mathrm{ACA}}\left(\tau_{\mathrm{a}}, \tau_{\mathrm{c}}\right) P_{i}\left(\tau_{\mathrm{a}}\right) \mathrm{d} \tau_{\mathrm{a}}\right] P\left(\tau_{\mathrm{c}}\right) \mathrm{d} \tau_{\mathrm{c}},
\end{aligned}
$$

where $P\left(\tau_{\mathrm{c}}\right)$ and $P_{i}\left(\tau_{\mathrm{a}}\right)$ are the PDF of below-aerosol COT and above-cloud AOT ( $i$ th CALIOP aerosol type), respectively. The advantage of Eq. (10) is that it allows $P\left(\tau_{\mathrm{c}}\right)$ and $P_{i}\left(\tau_{\mathrm{a}}\right)$ to be derived separately; thus tedious pixel-level collocation and pixel-by-pixel radiative transfer computations can be avoided. Following Zhang et al. (2014), we derive $P_{i}\left(\tau_{\mathrm{a}}\right)$ from the CALIOP level-2 aerosol layer product and $P\left(\tau_{\mathrm{c}}\right)$ from the joint histogram of cloud optical thickness and cloud top pressure (COT-CTP joint histogram) in the MODIS daily level-3 product. In order to speed up the calculations, we use pre-computed aerosol type-specific look-up tables (LUTs) instead of online radiative transfer computation when deriving the $\left\langle\mathrm{DRE}_{\mathrm{ACA}}\right\rangle_{i}$. The DRE LUTs are computed using the RRTM-SW (rapid radiative transfer model Shortwave) model (Clough et al., 2005; Iacono et al., 2008). For details about the computation of DRE LUTs readers are referred to (Zhang et al., 2014).

\subsection{COT retrieval correction for DRE computation}

When a cloudy pixel is contaminated by overlying lightabsorbing aerosols the MODIS COT retrieval is generally biased low (Coddington et al., 2010; e.g., Haywood et al., 2004). This COT retrieval bias needs to be accounted for in radiative transfer computation to avoid biased DRE (Meyer et al., 2013). A simple and fast correction scheme has been developed (Zhang et al., 2014) to account for the COT retrieval bias due to ACA in our DRE computation. First, we derive a MODIS LUT for "contaminated" clouds, which is essentially same as the operational MODIS LUT except that we put a layer of ACA on top of the cloud in the radiative transfer simulations to account for the impact of ACA on cloud reflectance. Then, we project the observed cloud reflectance that is contaminated by ACA onto the "contaminated" LUT to determine the corrected COT. This process is essentially to shift the potentially biased MODIS $P\left(\tau_{\mathrm{c}}\right)$ to a new "unbiased" PDF $P^{\prime}\left(\tau_{\mathrm{c}}\right)$ that is actually used in the DRE computation. It should be noted that because different aerosol types can have different impacts on the MODIS COT retrievals, the COT bias is dependent on the radiative properties of the ACA, and the correction process is therefore dependent on the assumed aerosol model. Hereafter, all DRE computations are based on the "unbiased" COT unless otherwise stated.

It is important to keep in mind that this COT correction scheme is only designed to account for the ACA-induced biases in the grid-level COT statistics. As shown in Zhang et al. (2014), the DRE computations based on this simple scheme agree very well with results based on more rigorous pixel-level corrections. However, this statistical scheme is not intended for deriving the unbiased COT at pixel level. Interested readers can refer to Meyer et al. (2015) for a novel method to simultaneously retrieve the AOT of ACA and the unbiased COT and CER of the underlying cloud at the pixel level.

\subsection{Aerosol optical properties}

As shown in Fig. 3, CALIOP-observed ACAs in the four ACA regions are primarily dust, smoke, and polluted dust aerosols. Given the AOT and underlying surface brightness, the DRE of aerosols is mainly determined by their optical properties, in particular single-scattering albedo. Therefore, the aerosol optical model assumption has a significant impact on the DRE results. In the control run shown in Sect. 5, we choose to build our aerosol optical property models to be as consistent as possible to the models used in the operational CALIOP retrieval algorithm (Omar et al., 2009), with specifications given below.

1. Smoke - In the control run, we use the model described in Omar et al. (2009) for smoke aerosols to be consistent with the CALIOP operational retrieval algorithm (referred to hereafter as "CALIOP smoke"). Figure 4a shows the optical properties of CALIOP smoke calculated using Mie code (Wiscombe, 1980), including extinction efficiency $\left(Q_{\mathrm{e}}\right)$, single-scattering albedo $(\omega)$ and asymmetry factor $(g)$ for the 14 RRTM-SW bands. In the calculation, we assumed a bimodal lognormal size distribution and a single refractive index of $1.517+0.023 i$ for all wavelengths (Omar et al., 2009). The band-averaged single-scattering albedo of CALIOP smoke is about 0.85 in the visible spectral region.

2. Dust - In the control run, the bulk scattering properties of dust aerosols shown in Fig. $4 \mathrm{c}$ are calculated using the bimodal lognormal size distributions in Omar et al. (2009) to be consistent with the operational CALIOP retrievals. For DRE computation, the refractive index over the whole solar spectrum is needed. However, in Omar et al. (2009), the refractive index of dust is given only for the two wavelengths of CALIOP, i.e., 532 and $1064 \mathrm{~nm}$. Alternatively, we use the dust spectral refractive index data reported in Colarco et al. (2014) to combine with the size distributions in Omar et al. (2009) to derive the optical properties of dust. Colarco et al. (2014) evaluated the sensitivity of dust transport simulations in NASA's GEOS-5 climate model to dust particle shape and spectral refractive indices. Two sets of dust refractive indices are tested. One is a merger of remote sensing-based estimates of dust refractive indices in the shortwave (Colarco et al., 2002; Kim et al., 2011) with the (Shettle and Fenn, 1979) values in the longwave. Following Colarco et al. (2014) we refer to 
Table 2. The seasonal and annual mean of diurnally averaged cloudy-sky DREs due to ACA at TOA (numbers on the top in each cell), surface (numbers in the middle) and within atmosphere (numbers on bottom). The unit is $\mathrm{W} \mathrm{m}^{-2}$.

\begin{tabular}{llrrrcc}
\hline Region & DRE & DJF & MAM & JJA & SON & Annual \\
\hline SE Atlantic & DRE $_{\text {TOA }}$ & -0.02 & -0.04 & 0.41 & 0.44 & 0.21 \\
Ocean & DRE $_{\text {SFC }}$ & -0.21 & -0.15 & -0.56 & -0.49 & 0.93 \\
& DRE $_{\text {ATM }}$ & 0.19 & 0.11 & 0.98 & -0.34 & 0.56 \\
\hline TNE Atlantic & DRE $_{\text {TOA }}$ & -0.05 & -0.57 & -2.39 & -0.20 & -0.78 \\
Ocean & DRE $_{\text {SFC }}$ & -0.21 & -1.45 & -5.99 & -0.48 & 0.28 \\
& DRE $_{\text {ATM }}$ & 0.16 & 0.88 & 3.60 & -1.99 & 1.21 \\
\hline Arabian Sea & DRE $_{\text {TOA }}$ & -0.02 & -0.44 & -0.97 & -0.25 & -0.54 \\
& DRE $_{\text {SFC }}$ & -0.16 & -1.11 & -2.44 & -0.73 & -1.41 \\
& DRE $_{\text {ATM }}$ & 0.14 & 0.67 & 1.47 & 0.48 & 0.88 \\
\hline NW Pacific & DRE $_{\text {TOA }}$ & 0.01 & 0.05 & 0.08 & 0.01 & 0.04 \\
Ocean & DRE $_{\text {SFC }}$ & -0.03 & -0.07 & -0.07 & -0.01 & -0.05 \\
& DRE $_{\text {ATM }}$ & 0.04 & 0.12 & 0.15 & 0.03 & 0.09 \\
\hline \multirow{2}{*}{ Global Ocean } & DRE $_{\text {TOA }}$ & 0.00 & -0.02 & -0.06 & 0.01 & -0.02 \\
& DRE $_{\text {SFC }}$ & -0.04 & -0.11 & -0.27 & -0.07 & -0.13 \\
& DRE $_{\text {ATM }}$ & 0.04 & 0.09 & 0.20 & 0.08 & 0.11 \\
\hline
\end{tabular}
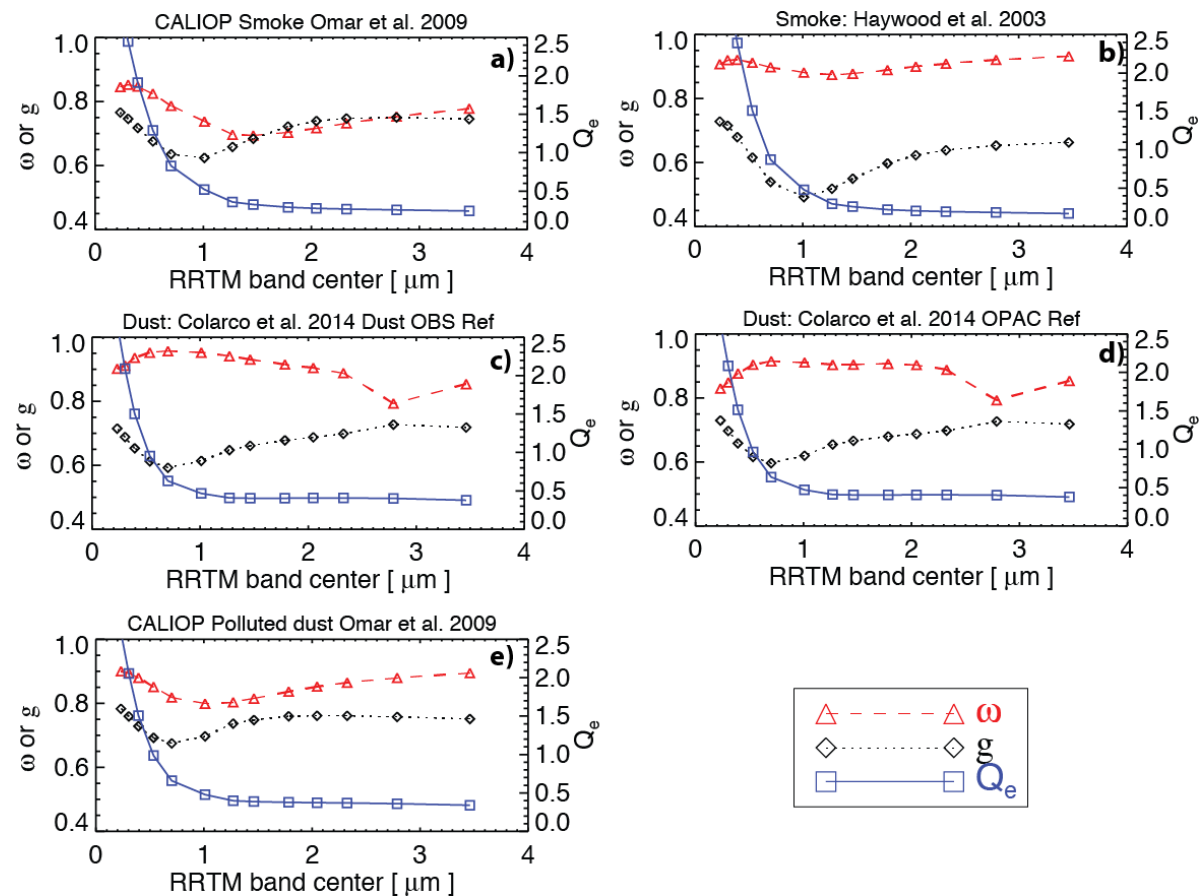

Figure 4. Single scattering properties, including extinction efficiency $\left(Q_{\mathrm{e}}\right)$, single-scattering albedo $(\omega)$, and asymmetry factor $(g)$ for $(\mathbf{a})$ CALIOP smoke, (b) Haywood smoke, (c) OBS dust, (d) OPAC dust and (e) CALIOP polluted dust.

this model hereafter as "OBS dust." The other one is based on the dust spectral refractive index provided in the OPAC database (OPAC, Hess et al., 1998; Colarco et al., 2014) (hereafter referred to as the "OPAC dust model"). The OPAC dust refractive index has been used for dust optical properties in previous studies by Perlwitz et al. (2001) and Colarco et al. (2010). In Colarco et al. (2014), OBS dust model is found to yield better dust clear-sky radiative forcing simulations in comparison with satellite observation. Therefore, we choose to use the OBS dust model in the control run. The OPAC dust model is more absorptive than the OBS model, which will be used in the uncertainty study to test the 

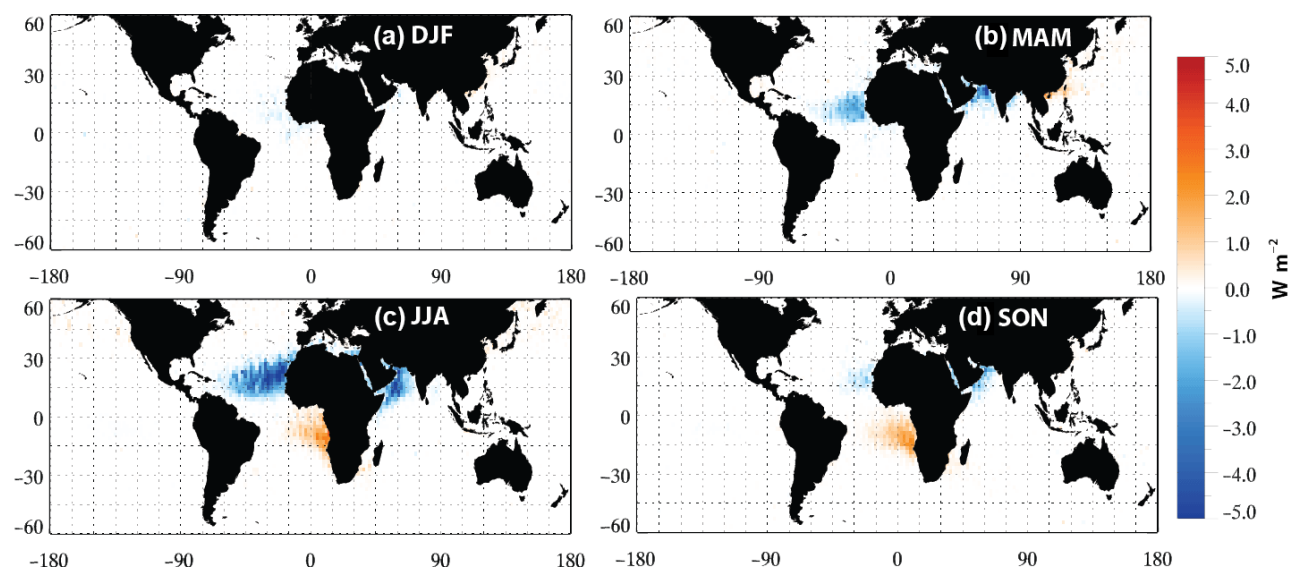

Figure 5. 8-year seasonal mean diurnally averaged shortwave cloudy-sky DRE at TOA, using the CALIOP smoke and OBS dust aerosol models. The ACA AOT in the computation is from the CALIOP operational product without any adjustment.

sensitivity of the DRE of above-cloud dust to its optical properties, in particular absorption.

3. Polluted dust - In the control run, we use the model described in Omar et al. (2009) to compute the scattering properties, shown Fig. 4e, of polluted dust aerosols identified by CALIOP. In the calculation, we assumed a bimodal lognormal size distribution and a single refractive index of $1.54+0.0019 i$ for all wavelengths.

In order to estimate the sensitivity of DRE of ACAs to their optical properties, we carried out a series of sensitivity studies using different aerosol optical models. The results from these sensitivity studies are discussed in Sect. 6.1.

\section{Shortwave cloudy-sky DREs due to ACA}

\subsection{Global and seasonal climatology}

Figure 5 shows the seasonal mean diurnally averaged shortwave cloudy-sky DRE at TOA $\left(\overline{\left\langle\operatorname{DRE}_{\text {cloudy-sky }}^{*}\right\rangle}\right.$ TOA $)$ derived from 8 years of MODIS and CALIOP data using the method described in the previous section. The computation uses the baseline optical models (i.e., "CALIOP smoke" and "OBS dust") described above. The regional and seasonal mean values are shown in Table 2 . It is not surprising that the regions with significant cloudy-sky DRE coincide with the regions of high ACA occurrence frequency (Fig. 2). Similar to previous studies, we found the cloudy-sky DRE in the SE Atlantic Ocean to be positive during the boreal summer (JJA) and fall (SON) seasons when the ACA is most active (Fig. 3a). The annual mean cloudy-sky DRE at TOA in this region is $0.21 \mathrm{~W} \mathrm{~m}^{-2}$ (Table 2) and the seasonal mean is as large as $0.44 \mathrm{~W} \mathrm{~m}^{-2}$ during SON. The TOA DRE is negative in the TNE Atlantic Ocean (annual mean $-0.78 \mathrm{~W} \mathrm{~m}^{-2}$ ) and the Arabian Sea (annual mean $-0.54 \mathrm{~W} \mathrm{~m}^{-2}$ ), where ACA is predominantly dust (Fig. 3b and c). This result suggests that the above cloud dust tends to have a cooling effect on the climate, similar to its clear-sky counterpart. The cloudysky DRE at TOA in the NW Pacific region is mostly positive and quite small (annual mean $0.04 \mathrm{~W} \mathrm{~m}^{-2}$ ), and is only noticeable in the boreal spring season (MAM) along the coast of China (Fig. 5b). Note that these numbers are not directly comparable to many previous studies (e.g., de Graaf et al., 2014; Feng and Christopher, 2015; Meyer et al., 2013) because the previous results are either instantaneous DRE that do not consider the diurnal variation of solar radiation, or are DRE averaged over only ACA pixels without accounting for the near zero DRE from "clean" clouds (i.e., not the true cloudy-sky DRE). When averaged over the global oceans, the positive DRE in the SE Atlantic is largely canceled out by the negative DRE of dust in the North Atlantic Ocean and the Arabian Sea, leading to an overall TOA DRE of about $-0.02 \mathrm{~W} \mathrm{~m}^{-2}$. Because most previous studies are focused on the SE Atlantic region, we cannot find other studies with which to compare our global DRE results. But we note that most AeroCom model simulations of global cloudysky aerosol DRE reported in Schulz et al. (2006) fall in the range of $-0.10-0.05 \mathrm{~W} \mathrm{~m}^{-2}$ (see their Table 5), although we understand our study is fundamentally different from Schulz et al. (2006).

Despite the large difference in TOA DRE, the DRE of ACA at the surface $\left(\overline{\left\langle D_{\text {cloudy-sky }}^{*}\right\rangle_{\text {surface }}}\right)$ is always negative (Fig. 6) and the DRE of ACA within atmosphere $\left(\overline{\left\langle\mathrm{DRE}_{\text {cloudy-sky }}^{*}\right\rangle_{\text {atm }}}\right)$ is always positive (Fig. 7), both as expected, in all of the active ACA regions. The annual mean cloudy-sky DREs at surface and within atmosphere averaged over global oceans are -0.13 and $0.11 \mathrm{~W} \mathrm{~m}^{-2}$, respectively (Table 2).

The 8-year time series of monthly mean cloudy-sky DRE at TOA due to the three most prevalent ACA types classified 

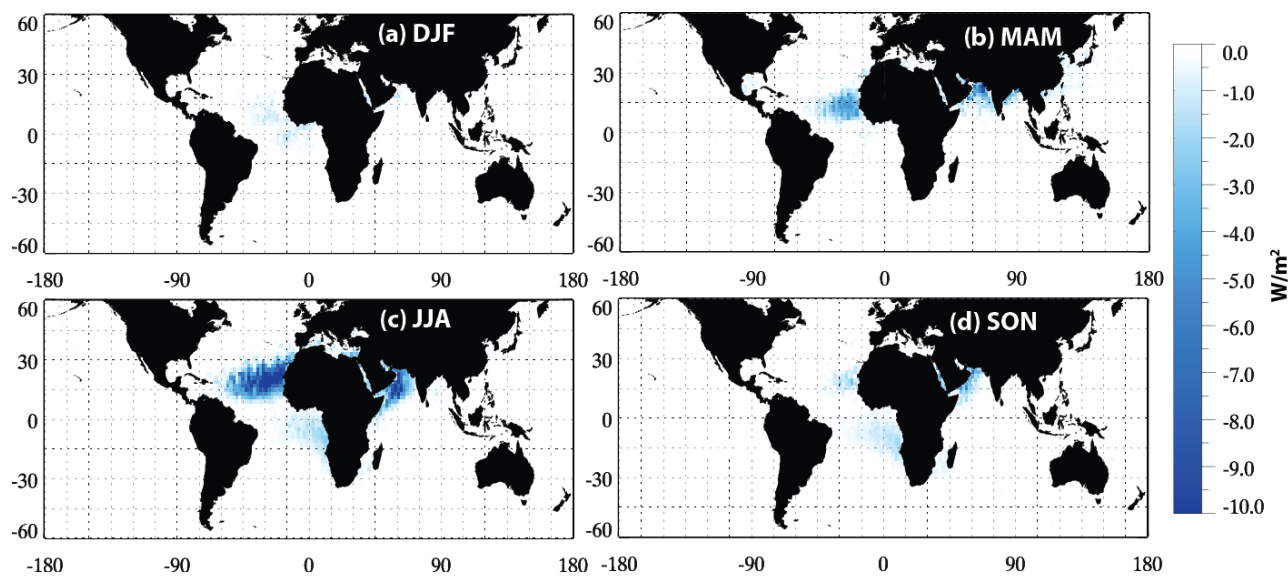

Figure 6. 8-year seasonal mean diurnally averaged shortwave cloudy-sky DRE at surface, using the CALIOP smoke and OBS dust aerosol models. The ACA AOT in the computation is from the CALIOP operational product without any adjustment.
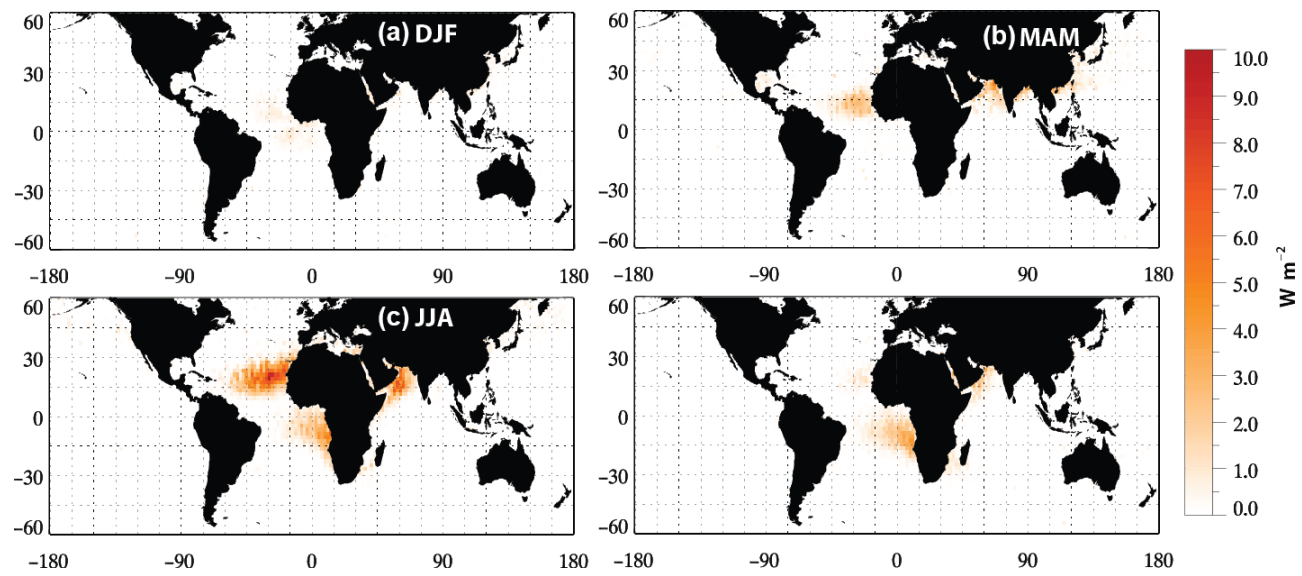

Figure 7. 8-year seasonal mean diurnally averaged shortwave cloudy-sky DRE within the atmosphere, using the CALIOP smoke and OBS dust aerosol models. The ACA AOT in the computation is from the CALIOP operational product without any adjustment.

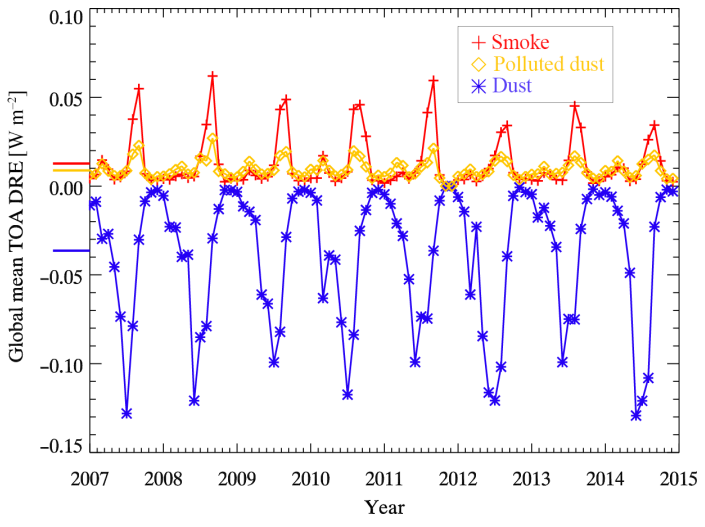

Figure 8. Time series of monthly mean diurnally averaged shortwave cloudy-sky DRE at TOA from 2007 to 2014. The horizontal bars on the $y$-axis mark the 8-year annual mean values. by CALIOP - smoke, polluted dust and dust - are shown in Fig. 8. As expected, the smoke ACA has a positive DRE with the peak value usually in September when the smoke is most active in the SE Atlantic region. The DRE of polluted dust ACA is generally positive, often with two peaks in the annual cycle - a larger one in boreal fall corresponding to the ACA active period in the SE Atlantic, and a smaller one usually in early boreal spring corresponding to the ACA active period in the NW Pacific. Together, the smoke and polluted dust have a combined annual mean DRE of about $0.03 \mathrm{~W} \mathrm{~m}^{-2}$ at TOA (see Table 3). Considering that the operational CALIOP retrievals often underestimate the AOT of ACA, the real DRE might be significantly larger. In fact, in the sensitivity test discussed in Sect. 6, the annual mean cloudy-sky TOA DRE from smoke and polluted dust can be up to about $0.06 \mathrm{~W} \mathrm{~m}^{-2}$, which is comparable to the radiative forcing from light absorbing aerosols on snow and ice (IPCC AR5). The dust ACA has a strong negative TOA DRE with a peak magnitude usually in July corresponding to the heavi- 
Table 3. The global annual mean of diurnally averaged cloudy-sky DREs at TOA induced by different types of ACA according to CALIOP observations. The numbers in the parentheses are results based on the scaled AOT (see Sect. 6 for details). The unit is $\mathrm{W} \mathrm{m}{ }^{-2}$.

\begin{tabular}{llrrr}
\hline Type & & $\begin{array}{r}\text { CALIOP } \\
\text { smoke+OBS dust }\end{array}$ & $\begin{array}{r}\text { Haywood } \\
\text { smoke+OBS dust }\end{array}$ & $\begin{array}{r}\text { CALIOP } \\
\text { smoke+OPAC dust }\end{array}$ \\
\hline Smoke & DRE $_{\text {TOA }}$ & $0.013(0.035)$ & $0.005(0.018)$ & $0.013(0.035)$ \\
& DRE $_{\text {SFC }}$ & $-0.011(-0.025)$ & $-0.021(-0.052)$ & $-0.011(-0.025)$ \\
& DRE $_{\text {ATM }}$ & $0.023(0.060)$ & $0.026(0.070)$ & $0.023(0.060)$ \\
\hline \multirow{2}{*}{ Dust } & DRE $_{\text {TOA }}$ & $-0.036(-0.044)$ & $-0.036(-0.044)$ & $-0.014(-0.014)$ \\
& DRE $_{\text {SFC }}$ & $-0.088(-0.116)$ & $-0.088(-0.116)$ & $-0.106(-0.141)$ \\
& DRE $_{\text {ATM }}$ & $0.051(0.071)$ & $0.051(0.071)$ & $0.092(0.127)$ \\
\hline \multirow{2}{*}{ Polluted dust } & DRE $_{\text {TOA }}$ & $0.009(0.019)$ & $0.009(0.019)$ & $0.009(0.019)$ \\
& DRE $_{\text {SFC }}$ & $-0.021(-0.035)$ & $-0.021(-0.035)$ & $-0.021(-0.035)$ \\
& DRE $_{\text {ATM }}$ & $0.030(0.054)$ & $0.030(0.054)$ & $0.030(0.054)$ \\
\hline
\end{tabular}

est dust period in the North Atlantic region (Fig. 3b). On the basis of these global ocean time series, we did not observe significant inter-annual variability.

\subsection{Regional analysis}

\subsubsection{SE Atlantic Ocean}

As seen in Fig. 3, the ACAs in the SE Atlantic region occur mostly during the dry season of the African Savanna (e.g., June to October) with peak frequency around August and September. According to CALIOP, the ACAs in this region consist mostly of smoke and polluted dust (Fig. 3a) that have significant absorption effects as shown in Fig. 4. Figure 9 provides an in-depth explanation of why the ACAs in this region generate a strong warming effect at TOA, as well as an insight into our method used for computing the DRE of ACA described in Sect. 4. The color contour in Fig. 9 corresponds to the diurnally averaged DRE at TOA as a function of the AOT of ACA and the COT of the underlying cloud, i.e., the $\operatorname{DRE}_{\mathrm{ACA}}\left(\tau_{\mathrm{a}}, \tau_{\mathrm{c}}\right)$ term in Eq. (9). The general patterns for smoke and polluted dust are quite similar, i.e., DRE is generally positive and increases with both AOT and COT. On the other hand, polluted dust has a smaller DRE than smoke for a given AOT and COT combination. As described in Sect. 4, the $\operatorname{DRE}_{\mathrm{ACA}}\left(\tau_{\mathrm{a}}, \tau_{\mathrm{c}}\right)$ is pre-computed off-line and is stored in a LUT to accelerate the computation. To obtain the spatially averaged DRE, $\left\langle\mathrm{DRE}_{\mathrm{ACA}}\right\rangle$, we integrate $\left\langle\mathrm{DRE}_{\mathrm{ACA}}\right\rangle$ with respect to the joint PDF of AOT and COT (i.e., the line contours in Fig. 9) that is derived from the CALIOP and MODIS observations as described in Sect. 4. As seen in Fig. 9a, during JJA the PDF of AOT has a peak slightly larger than 0.1 at $532 \mathrm{~nm}$. The COT PDF has two peaks, one around 3 and the other around 10. Compared to smoke, polluted dust in Fig. 9b has a smaller AOT with the PDF peaking at AOT slightly smaller than 0.1. The smaller AOT and weaker absorption together lead to a smaller DRE of polluted dust compared to smoke, as seen in Fig. 8.

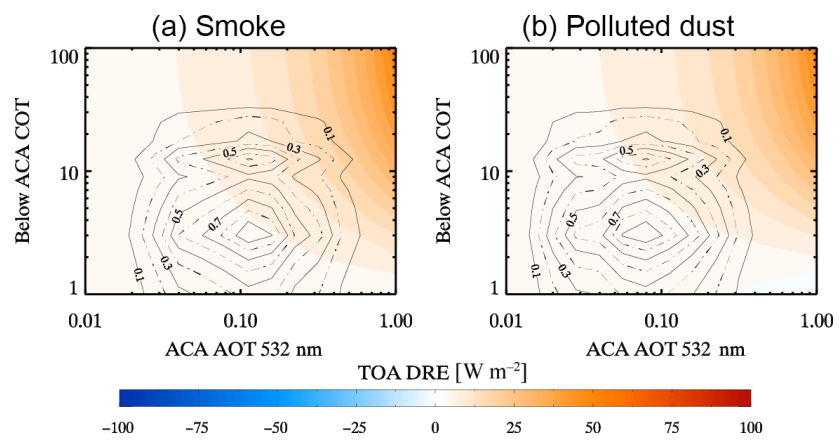

Figure 9. Diurnally averaged TOA above-cloud aerosol DRE as a function of COT and above-cloud AOT for the CALIOP smoke (a) and polluted dust (b) models. Also plotted for each aerosol model are the joint PDFs of above-cloud AOT and underlying COT (line contours); PDFs are obtained from the entire 8-year JJA record for the SE Atlantic region. Here, the solar zenith angle is assumed to be $24^{\circ}$ and CER is assumed to be $12.5 \mu \mathrm{m}$.

Figure 10 tells a similar story as Fig. 9, but from a different perspective. Here, we plotted the grid-mean DRE of ACA at TOA as a function grid-mean AOT of ACA based on observations from the SE Atlantic region. To show the importance of COT in modulating the ACA DRE we classify the data into three grid-mean COT bins, as indicated by the colors in the figure. In addition to the expected increase of DRE with AOT, we also notice that the slope of the DRE with respect to AOT, i.e., the DRE efficiency, generally increases with increasing grid-mean COT. The DRE efficiency for smoke is 17.9, 22.6 and $28.6 \mathrm{~W} \mathrm{~m}^{-2} /$ AOT for COT less than 4 , COT between 4 and 8 , and COT greater than 8 , respectively. The corresponding DRE efficiency for polluted dust is much smaller, yielding 6.7, 13.6, and $16.6 \mathrm{~W} \mathrm{~m}^{-2}$ /AOT, respectively. This result is not surprising given the $\operatorname{DRE}_{\mathrm{ACA}}\left(\tau_{\mathrm{a}}, \tau_{\mathrm{c}}\right)$ pattern in Fig. 9 and has also been noted in several pervious studies (Meyer et al., 2013; Yu et al., 2010; Zhang et al., 2014). Nevertheless, 


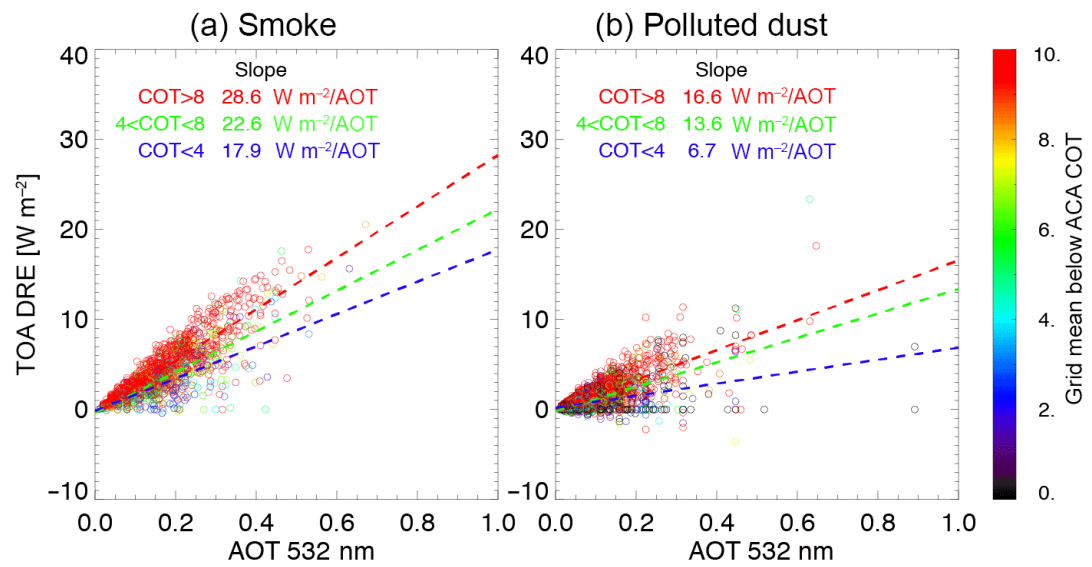

Figure 10. Dependence of grid-mean diurnally averaged DRE at TOA on grid-mean ACA AOT for (a) smoke and (b) polluted dust in the SE Atlantic Ocean from 8 years of CALIOP observations. The colors correspond to grid-mean underlying COT.

(a) ACA AOT 532nm

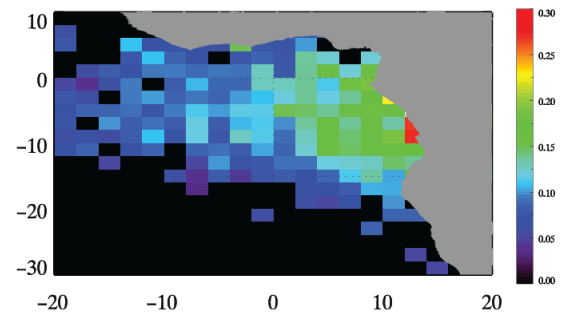

(c) cloudy-sky TOA DRE

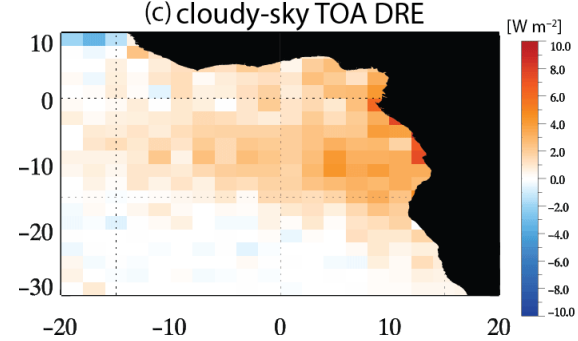

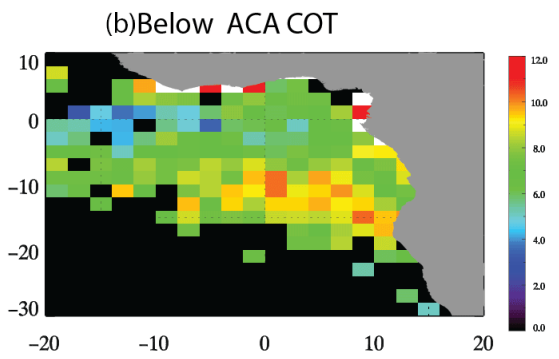

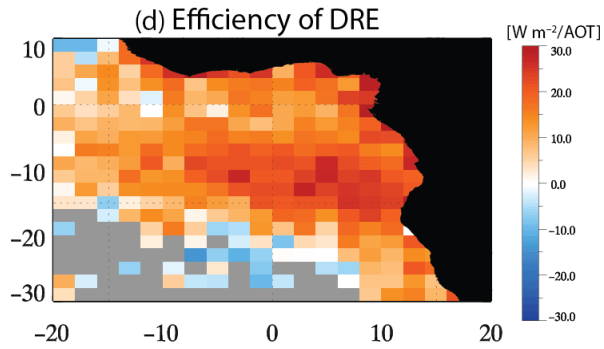

Figure 11. The 8-year seasonal mean (JJA) (a) AOT of ACA, (b) underlying COT, (c) cloudy-sky diurnally averaged DRE at TOA (W $\mathrm{m}^{-2}$ ), and (d) TOA DRE efficiency $\left(\mathrm{W} \mathrm{m}^{-2} \mathrm{AOT}^{-1}\right)$ in the SE Atlantic region.

it highlights the importance of cloud optical thickness (i.e., brightness) in determining the DRE efficiency of ACA.

Finally, Fig. 11 summarizes the multiyear seasonal meant ACA and cloud properties, as well as the DRE of ACA, in the SE Atlantic region during JJA. The seasonal mean total AOT of ACA at $532 \mathrm{~nm}$ (Fig. 11a), including all types of aerosols, is mainly between 0.1 to 0.2 , with the largest values found over the coastal region and reducing gradually toward the open sea presumably as a result of dry and/or wet deposition of smoke. The pattern of COT in Fig. 11b is more homogeneous (mostly between 6-8) except for a region of large values (around 10) along latitude $10^{\circ} \mathrm{S}$. Given the strong dependence of DRE on AOT in Figs. 9 and 10, it is not surprising to see that the seasonal mean cloudy sky DRE of ACA in the SE Atlantic region (Fig 11c) largely resembles the pattern of AOT (Fig. 11a). In contrast, the DRE efficiency in Fig. 11d aligns more with the COT pattern in Fig. 11b, as one would expect given the results in Fig. 10.

\subsubsection{TNE Atlantic Ocean and the Arabian Sea}

As discussed in Sect. 5.1, the TNE Atlantic Ocean and the Arabian Sea are an additional two regions with high occurrence frequency of ACA (Fig. 2). As shown in Fig. 3, dust aerosols are the dominant type of ACA in both regions with a general cooling effect at TOA (Fig. 5). An analysis similar to Figs. 9 and 10 but for the dust aerosols in the TNE Atlantic region and the Arabian Sea is shown in Fig. 12. A comparison of Fig. 12a with Fig. 9 reveals several important differences between the dust ACA-dominated region and the SE Atlantic smoke region. The color map in Fig. 12a reveals 

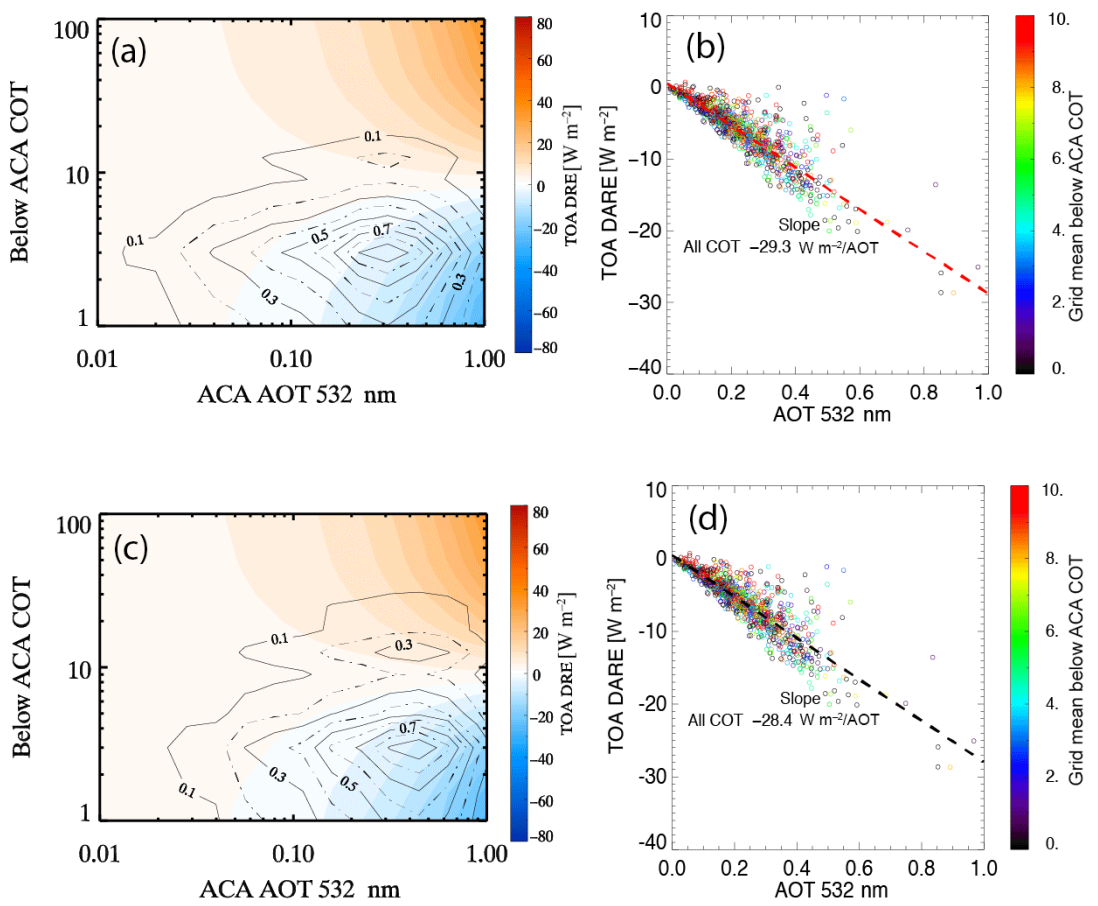

Figure 12. Same as Figs. 9 and 10 but for the dust aerosols in the TNE Atlantic region (a, b) and the Arabian Sea (c, d).

that above cloud dust with the optical properties in Fig. 4c in general has a cooling effect at TOA for COT smaller than about 7 . When the cloud becomes optically thicker, the DRE of above cloud dust at TOA switches sign to a warming effect. The line contour in Fig. 12a reveals that most of the clouds found in the TNE Atlantic region during JJA have a COT smaller than 10. As a result, the grid-mean DRE of ACA at TOA in this region is mostly negative as seen in both Fig. $12 \mathrm{~b}$ and previously in Fig. 5. It is interesting to note that the PDF of the AOT of above cloud dust has a peak value around 0.3 in Fig. 12a, which is larger than both the smoke and polluted dust in the SE Atlantic. This result reiterates the fact reported in many previous studies, that the sign of aerosol DRE at TOA is primarily determined by aerosol absorption, in particular with respect to the underlying surface, rather than aerosol loading. Similar to Fig. 10, we found in Fig. 12b that the grid-mean DRE in the TNE Atlantic region has a strong dependence on AOT; i.e., the magnitude of the negative DRE increases with increasing AOT. However, we found little dependence of grid-mean ACA DRE on gridmean COT in Fig. 12b in contrast to the case of smoke or polluted dust in Fig. 10. This result indicates that the grid-mean COT is not very revealing about the DRE of above-cloud dust. The overall DRE efficiency of above-cloud dust in this region based on grid-level statistics is $-29.3 \mathrm{~W} \mathrm{~m}^{-2}$ /AOT. The analysis for Arabian Sea in Fig. 12c and 12d turns out to be very similar to the TNE Atlantic region. The overall DRE efficiency of above-cloud dust in the Arabian Sea region is $-28.4 \mathrm{~W} \mathrm{~m}^{-2} /$ AOT. This result implies that the difference in the cloud-sky DRE between the TNE Atlantic Ocean and the Arabian Sea is mainly caused by the difference in ACA occurrence frequency $f_{\mathrm{ACA}}$ rather than aerosol or cloud property difference. For example, the JJA seasonal mean TOA DRE is $-2.39 \mathrm{~W} \mathrm{~m}^{-2}$ in TNE Atlantic vs. $-0.97 \mathrm{~W} \mathrm{~m}^{-2}$ in the Arabian Sea. This difference is mainly caused by the fact that the TNE Atlantic has a higher $f_{\mathrm{ACA}}$ around 0.4 than Arabian Sea around 0.15 (Fig. 3).

\subsubsection{NW Pacific Ocean}

The ACA in the NW Pacific Ocean has a small positive DRE at TOA, with a regional annual mean of only $0.04 \mathrm{~W} \mathrm{~m}^{-2}$ (Table 1). The positive DRE is primarily due to smoke and polluted dust aerosols (see Figs. 3 and 13). Note that CALIOP observes significantly more ACA in the NW Pacific region during nighttime (see Fig. S2 in the Supplement) than it does during daytime (Fig. 2). If this difference is due to CALIOP instrument issues (i.e., low signal-to-noise-ratio during daytime), it is then likely that the TOA DRE in Table 2 for the NW Pacific region is substantially underestimated. In Sect. 6, we estimated the impact of daytime vs. nighttime CALIOP aerosol retrieval differences on ACA DRE. Indeed, we found that the TOA DRE in the NW Pacific Ocean region significantly increases if nighttime CALIOP retrievals are used in DRE computations (regional annual mean increased up to $0.3 \mathrm{~W} \mathrm{~m}^{-2}$ ). Finally, we note in Table 2 that the peak value of seasonal mean TOA DRE in the northern Pacific Ocean occurs in the boreal summer (JJA) when the ACA occurrence frequency is low rather than in the spring 
(a) Smoke

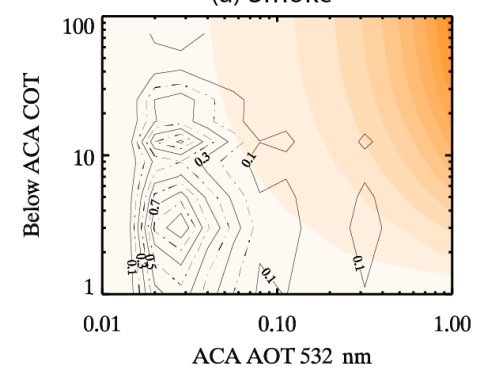

(b) Polluted dust

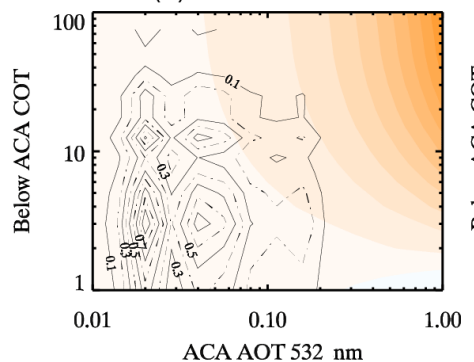

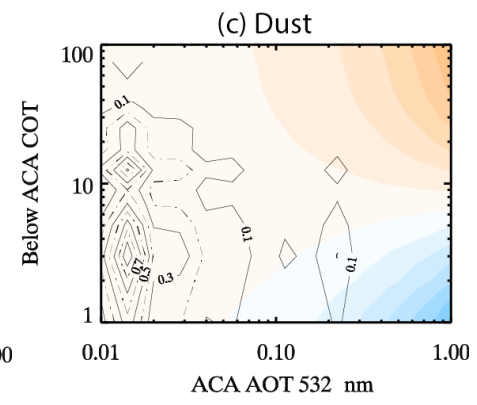

TOA DRE $\left[\mathrm{W} \mathrm{m}^{-2}\right]$

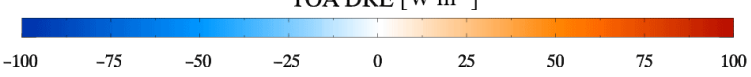

Figure 13. Same as Fig. 9 but for the (a) smoke, (b) polluted dust and (c) dust aerosols in the Northwest Pacific Ocean.

or winter when there is a larger ACA occurrence frequency. This suggests a stronger role of solar insolation than ACA occurrence frequency.

\section{Uncertainty analysis}

In this section, we assess the impact of two major uncertainties on the DRE computation, one associated with the aerosol optical properties and the other associated with the CALIOP AOT retrieval.

\subsection{Uncertainty in aerosol optical properties}

As indicated in Fig. 8, smoke and dust are the two most important types of ACA in terms of DRE. The DRE results in Sect. 5 are based on the control run, in which smoke and dust aerosols are represented by the CALIOP smoke model in Fig. 4a and OBS dust model in Fig. 4c. The primary rationale for using the CALIOP smoke model in the control run is that it is consistent with the operational CALIOP retrieval algorithm. As shown in Fig. 4a, the CALIOP smoke model has a single scattering albedo $\omega$ around 0.85 in the visible region, which is close to the mean value of $\omega$ measured during the SAFARI 2000 (Southern African Regional Science Initiative) field campaign (see Fig. 1 in Leahy et al., 2007). However, it should be noted that most measurements made during the SAFARI 2000 field campaign took place in the southern African continent close to the source of biomass burning aerosols and upstream of the SE Atlantic ACA region. Previous studies have found that the absorption of carbonaceous smoke particles tends to decrease due to the aging effect and mixing with other less absorptive aerosols ( $\mathrm{Li}$ ousse et al., 1993). In order to estimate the impact of aerosol model uncertainty on DRE, we replaced the CALIOP smoke model in our sensitivity tests with the less absorbing aged plume model reported in Haywood et al. (2003) (referred to as the "Haywood smoke model"). This model is derived from air-borne in situ measurements of aged smoke plumes advected off the coast of Namibia and Angola during the SA-
FARI 2000 campaign. In this model, in situ measured aerosol size distributions are fitted using a summation of three lognormal distributions with two fine modes composed of aged biomass smoke and the third coarse mode composed of mineral dust. The single scattering properties of the Haywood smoke model are shown in Fig. 4b. Compared to the CALIOP smoke model, the Haywood smoke model is significantly less absorptive, with a single scattering albedo $\omega$ of about 0.90 in the visible region (vs. $\omega \sim 0.85$ for the CALIOP smoke model).

To estimate the sensitivity of DRE to dust scattering properties, we developed a new dust scattering model based on the same size distribution as the OBS model but a different spectral refractive index provided in the OPAC database (Hess et al., 1998) (referred to as the "OPAC dust model"). The OPAC dust refractive index has been used for dust optical properties in previous studies by Perlwitz et al. (2001) and Colarco et al. (2010). The single scattering properties of the OPAC dust model are shown in Fig. 4d. With a $\omega \sim 0.9$ in the visible region, OPAC dust is significantly more absorptive than the OBS dust model ( $\omega \sim 0.95$ in visible) used in the control run. It should be clarified here that the new models do not necessarily provide a better (or worse) representation of the optical properties of ACA, but their differences from the models used in the control run, especially in terms of aerosol absorption, provide an opportunity to investigate the sensitivity of ACA DRE to the optical properties of ACA.

The results from the sensitivity tests are shown in Fig. 14. The annual mean cloudy-sky TOA DRE and DRE efficiency from the control run are shown in Figs. 14a and b. In the first sensitivity test, we replaced the CALIOP smoke model with the Haywood smoke model, but kept the OBS dust model. Note that the combination of Haywood smoke and OBS dust are the least absorptive among all possible combinations. As expected, the less absorbing Haywood smoke model leads to a significant reduction of positive DRE in the SE Atlantic Ocean (Fig. 14c). The annual and seasonal mean of cloudy-sky DRE in this region reduces by a factor of 2 

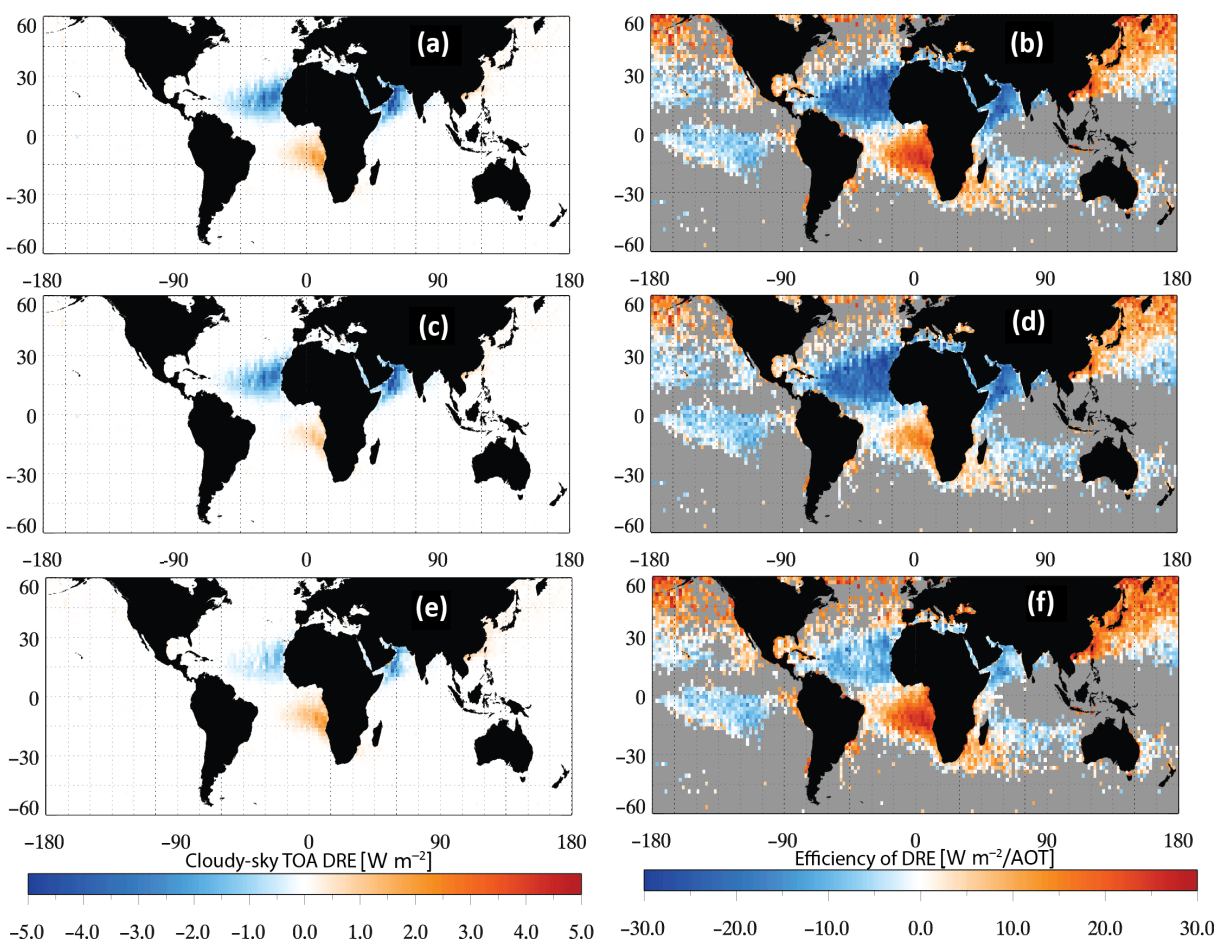

Figure 14. Annual mean cloudy-sky (a) DRE at TOA and (b) DRE efficiency due to ACA computed using the control run aerosol models; (c) and (d) are the same as (a) and (b), except that the CALIOP smoke model has been replaced by the Haywood smoke model; (e) and (f) are the same as (a) and (b), except that the OBS dust model has been replaced by the OPAC dust model.

from 0.21 to $0.10 \mathrm{~W} \mathrm{~m}^{-2}$. In addition, the DRE efficiency in Fig. $14 \mathrm{~d}$ is also seen to reduce significantly from a regional mean of $9.35 \mathrm{~W} \mathrm{~m}^{-2} / \mathrm{AOT}$ to $3.88 \mathrm{~W} \mathrm{~m}^{-2} / \mathrm{AOT}$. In the second sensitivity test, we replaced the OBS dust model with the OPAC dust model, but kept the CALIOP smoke model unchanged. Note that the combination of CALIOP smoke and OPAC dust are the most absorptive among all possible combinations. The use of the more absorptive OPAC model reduces the scattering effect of above-cloud dust, which has the most significant impact on the TNE Atlantic region as expected (Fig. 14e), reducing the strength of regional annual mean TOA DRE from -0.78 to $-0.31 \mathrm{~W} \mathrm{~m}^{-2}$. The regional mean DRE efficiency in the region reduces from about $-24.2 \mathrm{~W} \mathrm{~m}^{-2} / \mathrm{AOT}$ to $-9.5 \mathrm{~W} \mathrm{~m}^{-2} / \mathrm{AOT}$.

\subsection{Uncertainty in CALIOP AOT retrieval}

As mentioned in Sect. 2.1, several previous studies (Jethva et al., 2014; Torres et al., 2013; Waquet et al., 2013b) found that the current operational CALIOP $532 \mathrm{~nm}$ retrieval algorithm, based on the inversion of the attenuated backscatter profile, often significantly underestimates the AOT, especially for smoke aerosols and during the daytime. This is mainly because the strong attenuation of the upper part of an aerosol layer, plus the small backscatter of aerosol particles, makes the attenuated backscatter signal from the lower part of the layer too low to be detected, which leads to an underesti- mation of the physical thickness and thereby AOT of the aerosol layer. This issue is more severe for smoke aerosols than dust, due to the small backscatter of smoke aerosols (Liu et al., 2015). A case study of above-cloud smoke by (Jethva et al., 2014) showed that the AOT retrievals from other remote sensing techniques are substantially larger (up to a factor of 5) than the operational CALIOP $532 \mathrm{~nm}$ retrieval as a result of the abovementioned issue. A recent study by Liu et al. (2015) estimated that the operational CALIOP nighttime AOT retrieval for smoke aerosol over opaque clouds is underestimated by about $39 \%$. Because of the strong dependence of DRE on AOT, the underestimation of smoke AOT by the operational CALIOP retrieval algorithm would have substantially biased the DRE estimates discussed in Sect. 5, an effect that was shown previously in (Meyer et al., 2013). A robust quantification of this impact requires either the development and implementation of a new CALIOP retrieval algorithm or the use of an alternate independent data set of multiple year global ACA AOT retrievals, both of which are beyond the scope of this study. Here we attempt to estimate the upper bound of DRE bias due to the underestimate of AOT.

We note that although the CALIOP operational algorithm often misses the real bottom of an ACA layer, most of the time it can detect the top of the cloud beneath. This is because the strong backscatter of cloud droplets makes the attenuated backscatter signal strong enough for the CALIOP feature mask to detect despite the strong attenuation of the 


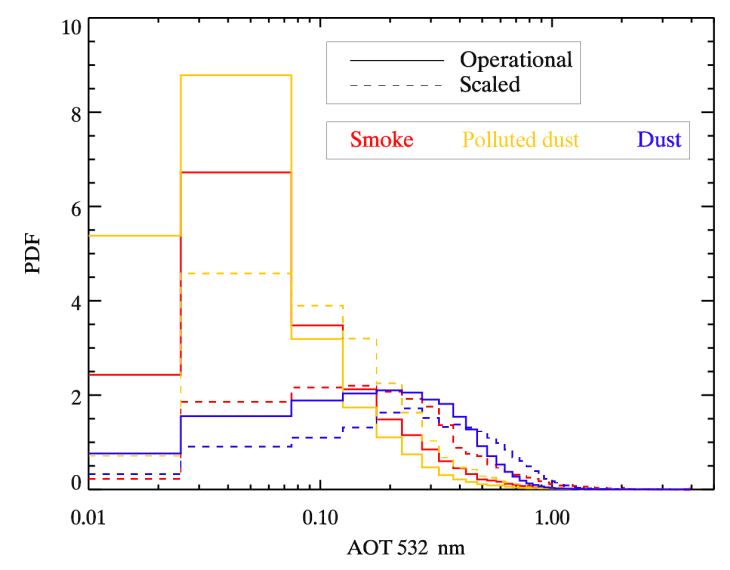

Figure 15. Comparison of the probability density function of abovecloud smoke AOT between the operational CALIOP retrieval (solid) and scaled result based on Eq. (11) (dashed). The comparison is based on 1 year (2008) of CALIOP data.

overlying ACA layer. Here we assume that the entire layer between the top of the ACA layer $\left(H_{\mathrm{ACA}-\mathrm{top}}\right)$ and the cloud top $\left(H_{\text {cloud-top }}\right)$ is occupied by aerosols, and we obtain the AOT for this entire layer by scaling the CALIOP AOT retrieval for ACA as follows:

$\tau_{\mathrm{ACA}}^{\prime}=\frac{H_{\text {ACA-top }}-H_{\text {cloud-top }}}{H_{\text {ACA-top }}-H_{\text {ACA-bottom }}^{*}} \tau_{\text {ACA }}$,

where $H_{\mathrm{ACA} \text {-bottom }}^{*}$ is the CALIOP retrieved apparent aerosol layer bottom height that is likely biased high. Because the true bottom of the aerosol layer is likely somewhere between the retrieved bottom and cloud top, the scaled AOT $\tau_{\mathrm{ACA}}^{\prime}$ is therefore an estimate of the upper limit of the ACA AOT. A comparison of the operational AOT retrievals and the scaled AOT based on Eq. (11) derived from 1 year of CALIOP data over global ocean is shown in Fig. 15. The scaling process systematically shifts the PDFs of AOT to larger values as expected. Globally averaged, the operational CALIOP $532 \mathrm{~nm}$ AOT for above-cloud smoke (with a mean value of 0.24 ) is about $43 \%$ smaller than the scaled results (mean value about 0.42 ). This result is encouragingly close to (and larger than) the estimate by Liu et al. (2015) (i.e., $39 \%$ underestimation), which seems to suggest that the bottom of the above-cloud smoke layer is much closer to cloud top than the daytime CALIOP observation. The scaling has a similar impact on polluted dust. In contrast, the impact on dust aerosols is smaller. The global mean AOT of above-cloud dust from the operational CALIOP product (mean AOT around 0.31) is about $30 \%$ smaller than the scaled result (mean AOT around $0.43)$. This is also close to the number reported in Liu et al. (2015) (i.e., $26 \%$ underestimation).

In the sensitivity test shown Fig. 16, we replaced the operational CALIOP $532 \mathrm{~nm}$ retrieval $\tau_{\mathrm{ACA}}$ with the scaled $\tau_{\mathrm{ACA}}^{\prime}$ in the DRE computation. In comparison with the DRE from the control run in Fig. 14a, c, and e, the most prominent change is the significant increase of positive TOA DRE in the SE Atlantic region, where ACAs are mostly smoke and polluted dust. For example, assuming the CALIOP smoke model, the regional annual mean TOA DRE increases from about $0.2 \mathrm{~W} \mathrm{~m}^{-2}$ if using the operational AOT to more than $0.6 \mathrm{~W} \mathrm{~m}^{-2}$ using the scaled AOT (see Table 4). Globally averaged, the annual mean TOA DRE induced by above-cloud smoke increases from about 0.013 to $0.035 \mathrm{~W} \mathrm{~m}^{-2}$ (see Table 3). Interestingly, the impact on DRE efficiency of AOT scaling is not as strong as the impact on DRE, suggesting that the DRE is generally linear with AOT as also found in previous studies (Meyer et al., 2013; Zhang et al., 2014).

In addition to the abovementioned issue, strong background solar noise is another source of uncertainty in the daytime CALIOP aerosol products (Hunt et al., 2009; Liu et al., 2015). To estimate the impact of this uncertainty on our DRE results, we performed another sensitivity test, in which we replaced the daytime CALIOP ACA retrievals, including AOT and aerosol classification, with the nighttime retrievals in our DRE computations. The results are presented in the Supplement. In summary, we found that CALIOP generally detects more and thicker above-cloud smoke in the nighttime than in the daytime, which has also been noted in previous studies (Meyer et al., 2013). We also noted that CALIOP generally detects less and thinner above-cloud dust in the nighttime than in the daytime. As a result of increased smoke and decreased dust, the annual mean global ocean DRE at TOA are shifted to more positive values, ranging from 0.0 to $0.06 \mathrm{~W} \mathrm{~m}^{-2}$ (see Table S1 in the Supplement), compared with the daytime results in Table $4\left(-0.03-0.04 \mathrm{~W} \mathrm{~m}^{-2}\right)$. We must emphasize that caution must be taken when interpreting the results from this test. Although solar noise certainly has an important role, other factors, in particular the natural aerosol diurnal cycle, could also cause differences between daytime and nighttime CALIOP aerosol retrievals. Future studies and independent data are needed to better understand these differences.

Yet another uncertainty source is the misclassification of aerosol as cloud, or vice versa, by CALIOP. According to Liu et al. (2009), overall the CALIOP cloud and aerosol discrimination algorithm works well in most cases. A 1-day manual verification suggests that the success rate is in the neighborhood of $90 \%$ or better. Misclassifications occur mostly in the source regions of dense of dust and smoke. Because this study focused on transported aerosols over ocean, the uncertainty caused by aerosol-cloud misclassification should be negligible in the comparison with other major uncertainties discussed above.

\subsection{Summary of uncertainty study}

Finally, combining the results from the control run (Table 3) and sensitivity tests (Table 4 and Table S2), we estimate that the annual mean diurnally average TOA DRE due to ACA over global ocean is about $0.015 \mathrm{~W} \mathrm{~m}^{-2}$ with a range 

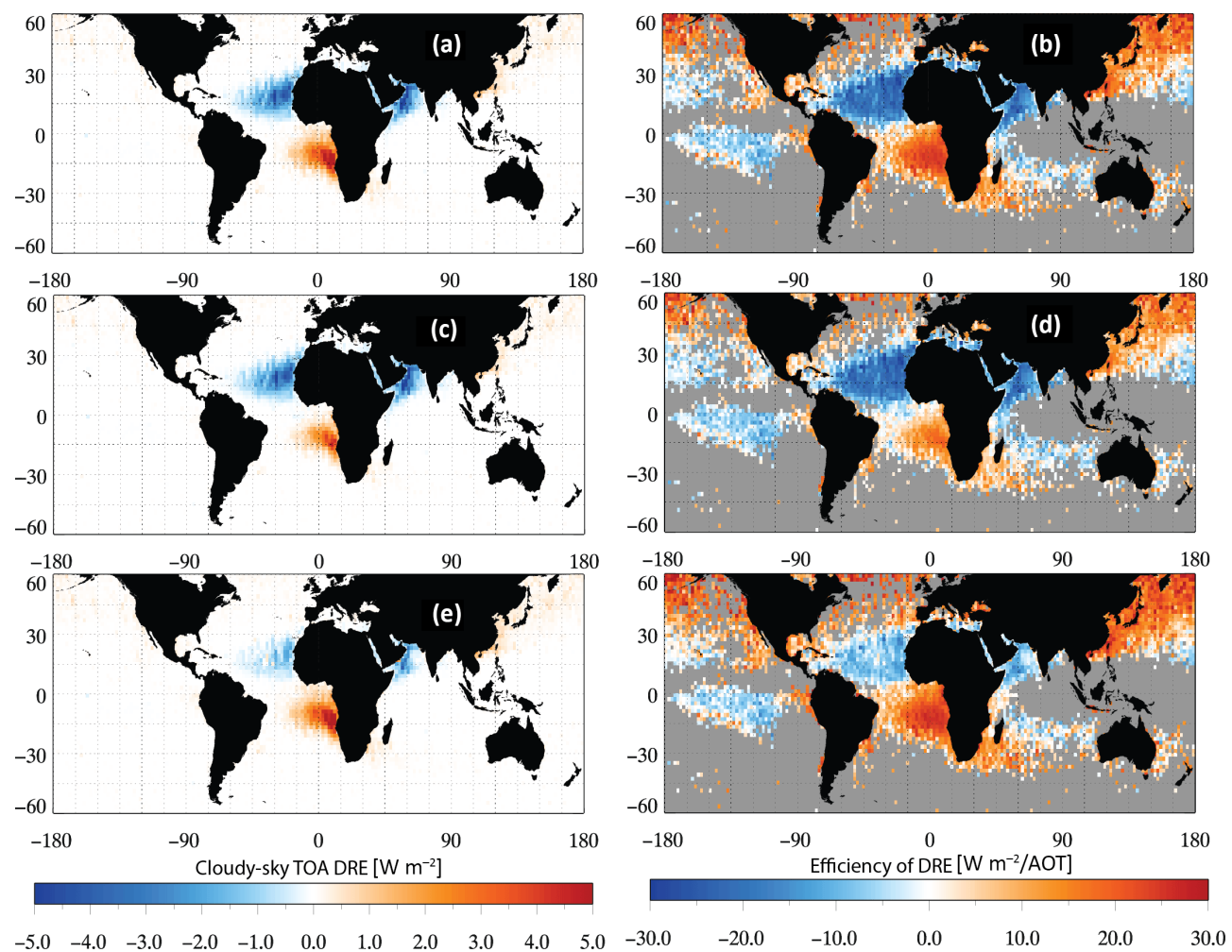

Figure 16. Same as Fig. 14, except that the scaled AOT based on Eq. (11) is used in the computations for smoke aerosols.

of -0.03 to $0.06 \mathrm{~W} \mathrm{~m}^{-2}$. The lower bound $\left(-0.03 \mathrm{~W} \mathrm{~m}^{-2}\right)$ is based on the combination of the least absorbing aerosol combination, i.e., Haywood smoke and OBS dust model, and operational (un-scaled) daytime AOT. The upper bound $\left(0.06 \mathrm{~W} \mathrm{~m}^{-2}\right)$ is based on the combination of the most absorbing aerosol models, i.e., CALIOP smoke and OPAC dust model, and scaled nighttime AOT. The DREs at surface and within the atmosphere are $-0.15 \mathrm{~W} \mathrm{~m}^{-2}$ (with a range of -0.09 to $-0.21 \mathrm{~W} \mathrm{~m}^{-2}$ ), and $0.17 \mathrm{~W} \mathrm{~m}^{-2}$ (with a range of 0.11 to $0.24 \mathrm{~W} \mathrm{~m}^{-2}$ ), respectively. It should be noted that the rather small TOA DRE when averaged over global ocean is partly because of the cancellation of positive (in SE Atlantic and NW Pacific) and negative (TNE Atlantic Ocean and the Arabian Sea) regional DREs. The regional and seasonal mean DREs, as shown in Table 5 and Table S3, could be much stronger. For example, in the SE Atlantic region, the JJA seasonal mean cloudy-sky DRE is about $0.7 \mathrm{~W} \mathrm{~m}^{-2}$ (with a range of 0.2 to $1.2 \mathrm{~W} \mathrm{~m}^{-2}$ ) at TOA (Table 5 and Table S3). From a different perspective, the results in Table 3 and Table S1 suggest that the light-absorbing ACAs, i.e., smoke and polluted dust, induce an annual mean TOA DRE of about $0.04 \mathrm{~W} \mathrm{~m}^{-2}$ (with a range of about $0.015-0.065 \mathrm{~W} \mathrm{~m}^{-2}$ ), which is largely canceled by the negative DRE due to abovecloud dust (annual mean of about $-0.024 \mathrm{~W} \mathrm{~m}^{-2}$ with a range between -0.004 to $-0.044 \mathrm{~W} \mathrm{~m}^{-2}$ ).

Overall, we found significant uncertainties in our DRE computation. Even the sign of global ocean mean cloud- sky TOA DRE is uncertain. This is partly because, as analyzed above, the positive DREs in regions dominated by light-absorbing ACAs (i.e., SE Atlantic and NW Pacific) are largely canceled by the negative DREs in the regions dominated by above-cloud dust (i.e., TNE Atlantic Ocean and The Arabian Sea). In addition, there are also substantial uncertainties in regional DREs caused by uncertainties in aerosol optical properties, in particular aerosol absorption, and uncertainties in the CALIOP operational aerosol retrieval products. Reducing these uncertainties requires improved knowledge of the optical properties of ACAs, in particular single-scattering albedo, on regional scales, and at the same time more accurate ACA property retrievals, in particular AOT. New measurements from upcoming field campaigns, for example NASA's ORACLES (ObseRvations of Aerosols above CLouds and their intEractionS), will help improve our knowledge of the ACA properties in SE Atlantic region. In addition, the emerging remote sensing techniques summarized in Yu and Zhang (2013) will provide independent ACA retrievals to compare and validate the results from this study and improve our understanding of the DRE of ACA. Finally, as pointed out earlier, we have ignored the cloud diurnal cycle in the DRE computation, as well as the uncertainty analysis in this section. The impact of cloud diurnal cycle on DRE computations will be investigated in future work along with updated uncertainty analysis. 
Table 4. The regional and annual mean of diurnally averaged cloudy-sky DREs at TOA based on different combinations of aerosol optical models. The numbers in the parentheses are results based on the scaled AOT (see Sect. 6 for details). The unit is $\mathrm{W} \mathrm{m}^{-2}$.

\begin{tabular}{llrrr}
\hline Region & & $\begin{array}{r}\text { CALIOP } \\
\text { smoke+OBS dust }\end{array}$ & $\begin{array}{r}\text { Haywood } \\
\text { smoke+OBS dust }\end{array}$ & $\begin{array}{r}\text { CALIOP } \\
\text { smoke+OPAC dust }\end{array}$ \\
\hline \multirow{2}{*}{ SE Atlantic } & DRE $_{\text {TOA }}$ & $0.21(0.67)$ & $0.10(0.38)$ & $0.23(0.68)$ \\
& DRE $_{\text {SFC }}$ & $-0.34(-0.73)$ & $-0.50(-1.13)$ & $-0.36(-0.76)$ \\
& DRE $_{\text {ATM }}$ & $0.56(1.37)$ & $0.59(1.51)$ & $0.60(1.44)$ \\
\hline \multirow{2}{*}{ TNE Atlantic } & DRE $_{\text {TOA }}$ & $-0.78(-1.00)$ & $-0.78(-0.99)$ & $-0.31(-0.34)$ \\
& DRE $_{\text {SFC }}$ & $-1.99(-2.68)$ & $-1.99(-2.67)$ & $-2.40(-3.22)$ \\
& DRE $_{\text {ATM }}$ & $1.22(1.69)$ & $1.21(1.70)$ & $2.09(2.88)$ \\
\hline \multirow{2}{*}{ Arabian Sea } & DRE $_{\text {TOA }}$ & $-0.54(-0.59)$ & $-0.54(-0.59)$ & $-0.25(-0.27)$ \\
& DRE $_{\text {SFC }}$ & $-1.41(-1.59)$ & $-1.42(-1.60)$ & $-1.67(-1.88)$ \\
& DRE $_{\text {ATM }}$ & $0.88(1.00)$ & $0.88(1.00)$ & $1.42(1.62)$ \\
\hline \multirow{2}{*}{ NW Pacific } & DRE $_{\text {TOA }}$ & $0.04(0.12)$ & $0.04(0.10)$ & $0.05(0.14)$ \\
& DRE $_{\text {SFC }}$ & $-0.05(-0.12)$ & $-0.06(-0.16)$ & $-0.05(-0.13)$ \\
& DRE $_{\text {ATM }}$ & $0.09(0.24)$ & $0.1(0.26)$ & $0.10(0.27)$ \\
\hline \multirow{2}{*}{ Global Ocean } & DRE $_{\text {TOA }}$ & $-0.02(0.00)$ & $-0.03(-0.01)$ & $0.00(0.04)$ \\
& DRE $_{\text {SFC }}$ & $-0.13(-0.18)$ & $-0.14(-0.21)$ & $-0.14(-0.20)$ \\
& DRE $_{\text {ATM }}$ & $0.11(0.18)$ & $0.11(0.20)$ & $0.14(0.24)$ \\
\hline
\end{tabular}

Table 5. Same as Table 4, except for JJA seasonal mean.

\begin{tabular}{llccr}
\hline Region & & $\begin{array}{r}\text { CALIOP } \\
\text { smoke+OBS dust }\end{array}$ & $\begin{array}{r}\text { Haywood } \\
\text { smoke+OBS dust }\end{array}$ & $\begin{array}{r}\text { CALIOP } \\
\text { smoke+OPAC dust }\end{array}$ \\
\hline \multirow{2}{*}{ SE Atlantic } & DRE $_{\text {TOA }}$ & $0.41(1.12)$ & $0.21(0.67)$ & $0.44(1.17)$ \\
& DRE $_{\text {SFC }}$ & $-0.56(1.20)$ & $-0.85(-1.89)$ & $-0.58(-1.22)$ \\
& DRE $_{\text {ATM }}$ & $0.98(2.32)$ & $1.06(2.57)$ & $1.01(2.40)$ \\
\hline TNE Atlantic & DRE $_{\text {TOA }}$ & $-2.39(-3.05)$ & $-2.39(-3.06)$ & $-0.91(-1.03)$ \\
& DRE $_{\text {SFC }}$ & $-5.99(-8.10)$ & $-5.99(-8.10)$ & $-7.26(-9.80)$ \\
& DRE $_{\text {ATM }}$ & $3.60(5.04)$ & $3.60(5.04)$ & $6.35(8.77)$ \\
\hline \multirow{2}{*}{ Arabian Sea } & DRE $_{\text {TOA }}$ & $-0.97(-1.06)$ & $-0.97(-1.07)$ & $-0.46(-0.49)$ \\
& DRE $_{\text {SFC }}$ & $-2.44(-2.76)$ & $-2.44(-2.76)$ & $-2.92(-3.30)$ \\
& DRE $_{\text {ATM }}$ & $1.47(1.70)$ & $1.47(1.70)$ & $2.46(2.81)$ \\
\hline \multirow{2}{*}{ NW Pacific } & DRE $_{\text {TOA }}$ & $0.08(0.22)$ & $0.06(0.19)$ & $0.09(0.24)$ \\
& DRE $_{\text {SFC }}$ & $-0.07(-0.20)$ & $-0.10(-0.27)$ & $-0.08(-0.20)$ \\
& DRE $_{\text {ATM }}$ & $0.15(0.41)$ & $0.16(0.46)$ & $0.17(0.44)$ \\
\hline \multirow{2}{*}{ Global Ocean } & DRE $_{\text {TOA }}$ & $-0.06(-0.04)$ & $-0.08(-0.06)$ & $0.00(0.03)$ \\
& DRE $_{\text {SFC }}$ & $-0.27(-0.38)$ & $-0.28(-0.42)$ & $-0.31(-0.44)$ \\
& DRE $_{\text {ATM }}$ & $0.20(0.34)$ & $0.21(0.36)$ & $0.31(0.47)$ \\
\hline
\end{tabular}

\section{Summary and discussion}

In this study, we used 8 years (2007-2014) of CALIOP ACA and MODIS cloud observations to derive the shortwave DRE of ACA over global oceans. The main findings are summarized below:

1. Similar to previous studies, we found high occurrence frequency of ACA in several regions of the globe (see Fig. 2), including (i) the SE Atlantic, where ma- rine boundary layer clouds are persistently covered by smoke and polluted dust aerosols originating from biomass burning activities in the African Savanna; (ii) the TNE Atlantic region, where ACAs are predominately blown dust from the Sahara; (iii) the Arabian Sea region, where dust aerosols from surrounding deserts overlap with clouds associated with the Asian monsoon; and (iv) the northern Pacific region, where transported 
pollution from Asia is often found above clouds in boreal winter and early spring (see Fig. 3).

2. In regions where ACAs are dominated by smoke and polluted dust (e.g., SE Atlantic and northern Pacific), the cloudy-sky DRE at TOA due to ACA is generally positive, while in regions dominated by dust aerosols (e.g., TNE Atlantic Ocean and the Arabian Sea) the DRE at TOA is generally negative (see Fig. 5). After averaging over global oceans, the light-absorptive ACAs, i.e., smoke and polluted dust, yield a TOA DRE of about $0.04 \mathrm{~W} \mathrm{~m}^{-2}$ (range of about $0.015-$ $0.065 \mathrm{~W} \mathrm{~m}^{-2}$ ). In contrast, above-cloud dusts yield an annual mean of about $-0.024 \mathrm{~W} \mathrm{~m}^{-2}$ (range of -0.004 to $-0.044 \mathrm{~W} \mathrm{~m}^{-2}$ ) (see Table 3 ). The cancellation of positive and negative DREs results in a rather small global-ocean averaged annual mean cloudy-sky TOA DRE of about $0.015 \mathrm{~W} \mathrm{~m}^{-2}$ with a range of -0.03 to $0.06 \mathrm{~W} \mathrm{~m}^{-2}$. The global-ocean averaged annual mean cloudy-sky DREs at the surface and within the atmosphere are about $-0.15 \mathrm{~W} \mathrm{~m}^{-2}$ (range of -0.09 to $-0.21 \mathrm{~W} \mathrm{~m}^{-2}$ ), and $0.17 \mathrm{~W} \mathrm{~m}^{-2}$ (range of 0.11 to $0.24 \mathrm{~W} \mathrm{~m}^{-2}$ ), respectively.

3. We estimated the impacts on our DRE computation of two major sources of uncertainty, one associated with assumed aerosol optical properties and the other with potential CALIOP AOT retrieval biases. As expected, we found the DRE of ACA is highly sensitive to the aerosol absorption. The use of a less absorptive smoke model can reduce the positive TOA DRE in the SE Atlantic region by a factor of 2 (see Fig. 14 and Table 3). The impact of potential low biases in the CALIOP AOT retrieval due to the high bias in the detected aerosol layer bottom is even stronger. The scaling has a stronger impact on the AOT of smoke than dust (see Fig. 15), leading to a less negative or even positive global annual mean DRE. The combination of AOT scaling and using more absorptive aerosol optical models can lead to a global-ocean averaged annual mean TOA DRE of about $0.04 \mathrm{~W} \mathrm{~m}^{-2}$ (see Table 4), and up to $0.06 \mathrm{~W} \mathrm{~m}^{-2}$ if nighttime CALIOP aerosol retrievals are used.

To our best knowledge, this is the first study to provide an observation-based global and multiyear perspective on the DRE of ACA. Our results can be used for evaluating and improving model simulations of cloudy-sky DRE of aerosols that currently have large diversity (Schulz et al., 2006).

There are several limitations to this study that could be improved upon in future work. First, as we mentioned in Sect. 4, although we consider the diurnal solar variation we ignored the diurnal variation of cloud and aerosol in our DRE computation. This is because the A-Train observes most regions of the globe only once during the daytime. This is not enough, especially in regions where clouds and/or aerosols have a strong diurnal cycle. For example, as shown in Min and Zhang (2014) the cloud fraction in the SE Atlantic region varies substantially from the maximum value of about $80 \%$ in the early morning to about $60 \%$ in the late afternoon. Cloud liquid water path and cloud optical thickness have a similar diurnal cycle (Wood et al., 2002). Approximating such a strong diurnal cycle using only the snapshot from the afternoon A-train crossing is likely to cause significant errors in DRE computation (Min and Zhang, 2014). In this regard, geostationary observations from, for instance, the SEVIRI (Spinning Enhanced Visible and InfraRed Imager) onboard MSG (MeteoSat Second Generation) (Schmetz et al., 2002), can be used to assess the impact of cloud diurnal cycle on ACA DRE computation. One of our future works will be using the diurnal cloud observations from SEVIRI and ACA observations from CALIOP or other satellite instruments to study the impact of cloud diurnal cycle on all-sky aerosol forcing in the SE Atlantic region. Second, we used only the aerosol retrievals from CALIOP in DRE computation. As aforementioned, recent studies have found significant biases and uncertainties in the operational CALIOP aerosol product (Jethva et al., 2014; Liu et al., 2015; Meyer et al., 2013). We have tried to estimate the impact of CALIOP retrieval uncertainties on our DRE computations. Nevertheless, future study is needed to better understand the uncertainties in our results. The emerging ACA property retrievals from the passive satellite sensors would provide independent data sets for such studies (Jethva et al., 2013; Meyer et al., 2015; Torres et al., 2011; Waquet et al., 2009). Finally, our current knowledge on the microphysical and optical properties of ACAs is still very limited due to the lack of measurements in comparison with clear-sky aerosols (e.g., no measurement from AERONET). New measurements from upcoming field campaigns, for example NASA's ORACLES (ObseRvations of Aerosols above CLouds and their intEractionS), and emerging satellite remote sensing techniques will help improve our DRE computations in the future.

\section{The Supplement related to this article is available online at doi:10.5194/acp-16-2877-2016-supplement.}

Acknowledgements. Z. Zhang is supported by NASA grant NNX14AI35G managed by Dr. Ming-Ying Wei. K. Meyer acknowledges support by the NASA Radiation Sciences Program, and by funding from NASA CloudSat and CALIPSO Science Team grant (NNH14CK44C) managed by Dr. David Considine. $\mathrm{H}$. Yu was supported by the NASA CALIPSO/CloudSat project (NNX14AB21G) managed by Dr. David Considine. The computations in this study were performed on UMBC High Performance Computing Facility (HPCF). The facility is supported by the U.S. National Science Foundation through the MRI program (grant nos. CNS-0821258 and CNS-1228778) and the SCREMS program (grant no. DMS-0821311), with additional substantial support from UMBC. 
Edited by: P. Stier

\section{References}

Abel, S. J., Highwood, E. J., Haywood, J. M., and Stringer, M. A.: The direct radiative effect of biomass burning aerosols over southern Africa, Atmos. Chem. Phys., 5, 1999-2018, doi:10.5194/acp-5-1999-2005, 2005.

Ackerman, S., Strabala, K., Menzel, W., Frey, R., Moeller, C., and Gumley, L.: Discriminating clear sky from clouds with MODIS, J. Geophys. Res., 103, 32141-32157, 1998.

Baum, B. A., Menzel, W. P., Frey, R. A., Tobin, D. C., Holz, R. E., Ackerman, S. A., Heidinger, A. K., and Yang, P.: MODIS CloudTop Property Refinements for Collection 6, J. Appl. Meteor. Climatol., 51, 1145-1163, doi:10.1175/JAMC-D-11-0203.1, 2012.

Burton, S. P., Ferrare, R. A., Vaughan, M. A., Omar, A. H., Rogers, R. R., Hostetler, C. A., and Hair, J. W.: Aerosol classification from airborne HSRL and comparisons with the CALIPSO vertical feature mask, Atmos. Meas. Tech., 6, 13971412, doi:10.5194/amt-6-1397-2013, 2013.

Chand, D., Anderson, T. L., Wood, R., Charlson, R. J., Hu, Y., Liu, Z., and Vaughan, M.: Quantifying above-cloud aerosol using spaceborne lidar for improved understanding of cloudysky direct climate forcing, J. Geophys. Res., 113, D13206, doi:10.1029/2007JD009433, 2008.

Chand, D., Wood, R., Anderson, T. L., Satheesh, S. K., and Charlson, R. J.: Satellite-derived direct radiative effect of aerosols dependent on cloud cover, Nature Geosci., 2, 181-184, doi:10.1038/ngeo437, 2009.

Clough, S. A., Shephard, M. W., Mlawer, E. J., Delamere, J. S., Iacono, M. J., Cady-Pereira, K., Boukabara, S., and Brown, P. D.: Atmospheric radiative transfer modeling: a summary of the AER codes, J. Quant. Spectrosc. Ra., 91, 233-244, 2005.

Coddington, O. M., Pilewskie, P., Redemann, J., Platnick, S., Russell, P. B., Schmidt, K. S., Gore, W. J., Livingston, J., Wind, G., and Vukicevic, T.: Examining the impact of overlying aerosols on the retrieval of cloud optical properties from passive remote sensing, J. Geophys. Res., 115, D10211, doi:10.1029/2009JD012829, 2010.

Colarco, P. R., Toon, O. B., Torres, O., and Rasch, P. J.: Determining the UV imaginary index of refraction of Saharan dust particles from Total Ozone Mapping Spectrometer data using a threedimensional model of dust transport, J. Geophys. Res., 107, AAC 4-1-AAC 4-18, doi:10.1029/2001JD000903, 2002.

Colarco, P., da Silva, A., Chin, M., and Diehl, T.: Online simulations of global aerosol distributions in the NASA GEOS-4 model and comparisons to satellite and ground-based aerosol optical depth, J. Geophys. Res., 115, D14207, doi:10.1029/2009JD012820, 2010.

Colarco, P. R., Nowottnick, E. P., Randles, C. A., Yi, B., Yang, P., Kim, K. M., Smith, J. A., and Bardeen, C. G.: Impact of radiatively interactive dust aerosols in the NASA GEOS-5 climate model: Sensitivity to dust particle shape and refractive index, J. Geophys. Res.-Atmos., 119, 753-786, doi:10.1002/2013JD020046, 2014.

de Graaf, M., Tilstra, L. G., Wang, P., and Stammes, P.: Retrieval of the aerosol direct radiative effect over clouds from spaceborne spectrometry, J. Geophys. Res., 117, D07207, doi:10.1029/2011JD017160, 2012.

de Graaf, M., Bellouin, N., Tilstra, L. G., Haywood, J., and Stammes, P.: Aerosol direct radiative effect of smoke over clouds over the southeast Atlantic Ocean from 2006 to 2009, Geophys. Res. Lett., 41, 7723-7730, doi:10.1002/2014GL061103, 2014.

Devasthale, A. and Thomas, M. A.: A global survey of aerosol-liquid water cloud overlap based on four years of CALIPSO-CALIOP data, Atmos. Chem. Phys., 11, 1143-1154, doi:10.5194/acp-11-1143-2011, 2011.

Eck, T. F., Holben, B. N., Reid, J. S., Mukelabai, M. M., Piketh, S. J., Torres, O., Jethva, H. T., Hyer, E. J., Ward, D. E., Dubovik, O., Sinyuk, A., Schafer, J. S., Giles, D. M., Sorokin, M., Smirnov, A., and Slutsker, I.: A seasonal trend of single scattering albedo in southern African biomass-burning particles: Implications for satellite products and estimates of emissions for the world's largest biomass-burning source, J. Geophys. Res.-Atmos., 118, 6414-6432, doi:10.1002/jgrd.50500, 2013.

Feng, N. and Christopher, S. A.: Measurement-based estimates of direct radiative effects of absorbing aerosols above clouds, J. Geophys. Res.-Atmos., 120, 2015JD023252, doi:10.1002/2015JD023252, 2015.

Haywood, J. M., Osborne, S. R., Francis, P. N., Keil, A., Formenti, P., Andreae, M. O., and Kaye, P. H.: The mean physical and optical properties of regional haze dominated by biomass burning aerosol measured from the C-130 aircraft during SAFARI 2000 , J. Geophys. Res., 108, 8473, doi:10.1029/2002JD002226, 2003.

Haywood, J. M., Osborne, S. R., and Abel, S. J.: The effect of overlying absorbing aerosol layers on remote sensing retrievals of cloud effective radius and cloud optical depth, Q. J. Roy. Meteorol. Soc., 130, 779-800, doi:10.1256/qj.03.100, 2004.

Hess, M., Koepke, P., and Schult, I.: Optical Properties of Aerosols and Clouds: The Software Package OPAC, B. Am. Meteor. Soc., 79, 831-844, doi:10.1175/15200477(1998)079<0831:OPOAAC>2.0.CO;2, 1998.

Hu, Y., Vaughan, M., Liu, Z., Lin, B., Yang, P., Flittner, D., Hunt, B., Kuehn, R., Huang, J., Wu, D., Rodier, S., Powell, K., Trepte, C., and Winker, D.: The depolarization - attenuated backscatter relation: CALIPSO lidar measurements vs. theory, Opt. Express, 15, 5327-5332, doi:10.1364/OE.15.005327, 2007.

Hubanks, P. A., King, M. D., Platnick, S., and Pincus, R.: MODIS atmosphere L3 gridded product algorithm theoretical basis document, Algorithm Theor. Basis Doc. ATBD-MOD, 30, 2008.

Hunt, W. H., Winker, D. M., Vaughan, M. A., Powell, K. A., Lucker, P. L., and Weimer, C.: CALIPSO Lidar Description and Performance Assessment, J. Atmos. Ocean. Technol., 26, 1214-1228, doi:10.1175/2009JTECHA1223.1, 2009.

Iacono, M. J., Delamere, J. S., Mlawer, E. J., Shephard, M. W., Clough, S. A., and Collins, W. D.: Radiative forcing by long-lived greenhouse gases: Calculations with the AER radiative transfer models, J. Geophys. Res., 113, D13103, doi:10.1029/2008JD009944, 2008.

Ichoku, C., Remer, L. A., Kaufman, Y. J., Levy, R., Chu, D. A., Tanré, D., and Holben, B. N.: MODIS observation of aerosols and estimation of aerosol radiative forcing over southern Africa during SAFARI 2000, J. Geophys. Res., 108, 8499, doi:10.1029/2002JD002366, 2003.

Jethva, H., Torres, O., Remer, L. A., and Bhartia, P. K.: A color ratio method for simultaneous retrieval of aerosol and cloud op- 
tical thickness of above-cloud absorbing aerosols from passive sensors: Application to MODIS measurements, IEEE T. Geosci. Remote, 51, 3862-3870, 2013.

Jethva, H., Torres, O., Waquet, F., Chand, D., and Hu, Y.: How do A-train sensors intercompare in the retrieval of above-cloud aerosol optical depth? A case study-based assessment, Geophys. Res. Lett., 41, 186-192, doi:10.1002/2013GL058405, 2014.

Keil, A. and Haywood, J. M.: Solar radiative forcing by biomass burning aerosol particles during SAFARI 2000: A case study based on measured aerosol and cloud properties, J. Geophys. Res., 108, 8467, doi:10.1029/2002JD002315, 2003.

Kim, D., Chin, M., Yu, H., Eck, T. F., Sinyuk, A., Smirnov, A., and Holben, B. N.: Dust optical properties over North Africa and Arabian Peninsula derived from the AERONET dataset, Atmos. Chem. Phys., 11, 10733-10741, doi:10.5194/acp-1110733-2011, 2011.

Leahy, L. V., Anderson, T. L., Eck, T. F., and Bergstrom, R. W.: A synthesis of single scattering albedo of biomass burning aerosol over southern Africa during SAFARI 2000, Geophys. Res. Lett., 34, L12814, doi:10.1029/2007GL029697, 2007.

Liousse, C., Cachier, H., and Jennings, S. G.: Optical and thermal measurements of black carbon aerosol content in different environments: Variation of the specific attenuation cross-section, sigma $(\sigma)$, Atmos. Environ. Part A. General Topics, 27, 12031211, doi:10.1016/0960-1686(93)90246-U, 1993.

Liu, Z., Vaughan, M., Winker, D., Kittaka, C., Getzewich, B., Kuehn, R., Omar, A., Powell, K., Trepte, C., and Hostetler, C.: The CALIPSOLidar Cloud and Aerosol Discrimination: Version 2 Algorithm and Initial Assessment of Performance, J. Atmos. Ocean. Tech., 26, 1198-1213, doi:10.1175/2009JTECHA1229.1, 2009.

Liu, Z., Winker, D., Omar, A., Vaughan, M., Kar, J., Trepte, C., $\mathrm{Hu}$, Y., and Schuster, G.: Evaluation of CALIOP $532 \mathrm{~nm}$ aerosol optical depth over opaque water clouds, Atmos. Chem. Phys., 15, 1265-1288, doi:10.5194/acp-15-1265-2015, 2015.

Marchant, B., Platnick, S., Meyer, K. G., Arnold, G. T., and Riedi, J.: MODIS Collection 6 shortwave-derived cloud phase classification algorithm and comparisons with CALIOP, Atmos. Chem. Phys., in preparation, 2015.

Matichuk, R. I., Colarco, P. R., Smith, J. A., and Toon, O. B.: Modeling the transport and optical properties of smoke aerosols from African savanna fires during the Southern African Regional Science Initiative campaign (SAFARI 2000), J. Geophys. Res., 112, D08203, doi:10.1029/2006JD007528, 2007.

Menzel, P., Frey, R., Baum, B., and Zhang, H.: Cloud Top Properties and Cloud Phase Algorithm Theoretical Basis Document, 2006.

Menzel, W., Smith, W., and Stewart, T.: Improved Cloud Motion Wind Vector and Altitude Assignment Using VAS, J. Appl. Meteorol., 22, 377-384, 1983.

Meyer, K., Platnick, S., Oreopoulos, L., and Lee, D.: Estimating the direct radiative effect of absorbing aerosols overlying marine boundary layer clouds in the southeast Atlantic using MODIS and CALIOP, J. Geophys. Res.-Atmos., 118, 48014815, doi:10.1002/jgrd.50449, 2013.

Meyer, K., Platnick, S., and Zhang, Z.: Simultaneously inferring above-cloud absorbing aerosol optical thickness and underlying liquid phase cloud optical and microphysical properties using MODIS, J. Geophys. Res.-Atmos., 120, 5524-5547, doi:10.1002/2015JD023128, 2015.
Min, M. and Zhang, Z.: On the influence of cloud fraction diurnal cycle and sub-grid cloud optical thickness variability on all-sky direct aerosol radiative forcing, J. Quant. Spectrosc. Ra., 142, 25-36, doi:10.1016/j.jqsrt.2014.03.014, 2014.

Myhre, G., Berntsen, T. K., Haywood, J. M., Sundet, J. K., Holben, B. N., Johnsrud, M., and Stordal, F.: Modeling the solar radiative impact of aerosols from biomass burning during the Southern African Regional Science Initiative (SAFARI-2000) experiment, J. Geophys. Res., 108, 8501, doi:10.1029/2002JD002313, 2003.

Nakajima, T. and King, M. D.: Determination of the Optical Thickness and Effective Particle Radius of Clouds from Reflected Solar Radiation Measurements. Part I: Theory, J. Atmos. Sci., 47, 1878-1893, doi:10.1175/15200469(1990)047<1878:DOTOTA>2.0.CO;2, 1990.

Nowottnick, E. P., Colarco, P. R., Welton, E. J., and da Silva, A.: Use of the CALIOP vertical feature mask for evaluating global aerosol models, Atmos. Meas. Tech., 8, 3647-3669, doi:10.5194/amt-8-3647-2015, 2015.

Omar, A. H., Winker, D. M., Vaughan, M. A., Hu, Y., Trepte, C. R., Ferrare, R. A., Lee, K.-P., Hostetler, C. A., Kittaka, C., and Rogers, R. R.: The CALIPSO automated aerosol classification and lidar ratio selection algorithm, J. Atmos. Ocean. Tech., 26, 1994-2014, 2009.

Perlwitz, J., Tegen, I., and Miller, R. L.: Interactive soil dust aerosol model in the GISS GCM: 1 . Sensitivity of the soil dust cycle to radiative properties of soil dust aerosols, J. Geophys. Res., 106, 18167-18192, doi:10.1029/2000JD900668, 2001.

Peters, K., Quaas, J., and Bellouin, N.: Effects of absorbing aerosols in cloudy skies: a satellite study over the Atlantic Ocean, Atmos. Chem. Phys., 11, 1393-1404, doi:10.5194/acp-11-13932011, 2011.

Platnick, S., King, M. D., Ackerman, S. A., Menzel, W. P., Baum, B. A., Riédi, J. C., and Frey, R. A.: The MODIS cloud products: algorithms and examples from Terra, IEEE T. Geosci. Remote, 41, 459-473, doi:10.1109/TGRS.2002.808301, 2003.

Schmetz, J., Pili, P., Tjemkes, S., Just, D., Kerkmann, J., Rota, S., and Ratier, A.: An Introduction to Meteosat Second Generation (MSG), B. Am. Meteor. Soc., 83, 977-992, doi:10.1175/15200477(2002)083<0977:AITMSG>2.3.CO;2, 2002.

Schulz, M., Textor, C., Kinne, S., Balkanski, Y., Bauer, S., Berntsen, T., Berglen, T., Boucher, O., Dentener, F., Guibert, S., Isaksen, I. S. A., Iversen, T., Koch, D., Kirkevåg, A., Liu, X., Montanaro, V., Myhre, G., Penner, J. E., Pitari, G., Reddy, S., Seland, $\varnothing .$, Stier, P., and Takemura, T.: Radiative forcing by aerosols as derived from the AeroCom present-day and pre-industrial simulations, Atmos. Chem. Phys., 6, 5225-5246, doi:10.5194/acp-65225-2006, 2006.

Shettle, E. P. and Fenn, R. W.: Models for the Aerosols of the Lower Atmosphere and the Effects of Humidity Variations on their Optical Properties, 1979.

Stephens, G. L., Vane, D. G., Boain, R. J., Mace, G. G., Sassen, K., Wang, Z., Illingworth, A. J., O'Connor, E. J., Rossow, W. B., Durden, S. L., Miller, S. D., Austin, R. T., Benedetti, A., Mitrescu, C., and CloudSat Science Team, T.: THE CLOUDSAT MISSION AND THE A-TRAIN,, 83, 1771-1790, doi:10.1175/BAMS-83-12-1771, 2002.

Swap, R., Garstang, M., Macko, S. A., Tyson, P. D., Maenhaut, W., Artaxo, P., Kållberg, P., and Talbot, R.: The long-range transport of southern African aerosols to the tropical South Atlantic, 
J. Geophys. Res., 101, 23777-23791, doi:10.1029/95JD01049, 1996.

Torres, O., Jethva, H., and Bhartia, P. K.: Retrieval of Aerosol Optical Depth above Clouds from OMI Observations: Sensitivity Analysis and Case Studies, J. Atmos. Sci., 69, 1037-1053, doi:10.1175/JAS-D-11-0130.1, 2011.

Torres, O., Ahn, C., and Chen, Z.: Improvements to the OMI nearUV aerosol algorithm using A-train CALIOP and AIRS observations, Atmos. Meas. Tech., 6, 3257-3270, doi:10.5194/amt-63257-2013, 2013.

Waquet, F., Riedi, J., C Labonnote, L., Goloub, P., Cairns, B., Deuzé, J. L., and Tanre, D.: Aerosol Remote Sensing over Clouds Using A-Train Observations, J. Atmos. Sci., 66, 2468-2480, doi:10.1175/2009JAS3026.1, 2009.

Waquet, F., Cornet, C., Deuzé, J.-L., Dubovik, O., Ducos, F., Goloub, P., Herman, M., Lapyonok, T., Labonnote, L. C., Riedi, J., Tanré, D., Thieuleux, F., and Vanbauce, C.: Retrieval of aerosol microphysical and optical properties above liquid clouds from POLDER/PARASOL polarization measurements, Atmos. Meas. Tech., 6, 991-1016, doi:10.5194/amt-6-991-2013, $2013 \mathrm{a}$.

Waquet, F., Peers, F., Ducos, F., Goloub, P., Platnick, S., Riedi, J., Tanre, D., and Thieuleux, F.: Global analysis of aerosol properties above clouds, Geophys. Res. Lett., 40, 5809-5814, doi:10.1002/2013GL057482, 2013b.

Wilcox, E. M.: Direct and semi-direct radiative forcing of smoke aerosols over clouds, Atmos. Chem. Phys., 12, 139-149, doi:10.5194/acp-12-139-2012, 2012.

Winker, D. M., Hunt, W. H., and McGill, M. J.: Initial performance assessment of CALIOP, Geophys. Res. Lett., 34, L19803, doi:10.1029/2007GL030135, 2007.

Winker, D. M., Vaughan, M. A., Omar, A., Hu, Y., Powell, K. A., Liu, Z., Hunt, W. H., and Young, S. A.: Overview of the CALIPSO mission and CALIOP data processing algorithms, J. Atmos. Ocean. Tech., 26, 2310-2323, 2009.

Winker, D. M., Tackett, J. L., Getzewich, B. J., Liu, Z., Vaughan, M. A., and Rogers, R. R.: The global 3-D distribution of tropospheric aerosols as characterized by CALIOP, Atmos. Chem. Phys., 13, 3345-3361, doi:10.5194/acp-13-3345-2013, 2013.
Wiscombe, W.: Improved Mie scattering algorithms, Appl. Opt, 19, 1505-1509, 1980.

Wood, R., Bretherton, C. S., and Hartmann, D. L.: Diurnal cycle of liquid water path over the subtropical and tropical oceans, Geophys. Res. Lett., 29, 7-1-7-4, doi:10.1029/2002GL015371, 2002.

Young, S. A. and Vaughan, M. A.: The Retrieval of Profiles of Particulate Extinction from Cloud-Aerosol Lidar Infrared Pathfinder Satellite Observations (CALIPSO) Data: Algorithm Description, J. Atmos. Ocean. Tech., 26, 1105-1119, doi:10.1175/2008JTECHA1221.1, 2008.

Yu, H. and Zhang, Z.: New Directions: Emerging satellite observations of above-cloud aerosols and direct radiative forcing, Atmos. Environ., 72, 36-40, doi:10.1016/j.atmosenv.2013.02.017, 2013.

Yu, H., Kaufman, Y. J., Chin, M., Feingold, G., Remer, L. A., Anderson, T. L., Balkanski, Y., Bellouin, N., Boucher, O., Christopher, S., DeCola, P., Kahn, R., Koch, D., Loeb, N., Reddy, M. S., Schulz, M., Takemura, T., and Zhou, M.: A review of measurement-based assessments of the aerosol direct radiative effect and forcing, Atmos. Chem. Phys., 6, 613-666, doi:10.5194/acp-6-613-2006, 2006.

Yu, H., Zhang, Y., Chin, M., Liu, Z., Omar, A., Remer, L. A., Yang, Y., Yuan, T., and Zhang, J.: An integrated analysis of aerosol above clouds from A-Train multi-sensor measurements, Remote Sens. Environ., 121, 125-131, doi:10.1016/j.rse.2012.01.011, 2010.

Zhang, Z., Meyer, K., Platnick, S., Oreopoulos, L., Lee, D., and Yu, H.: A novel method for estimating shortwave direct radiative effect of above-cloud aerosols using CALIOP and MODIS data, Atmos. Meas. Tech., 7, 1777-1789, doi:10.5194/amt-71777-2014, 2014. 